\title{
Validation of OMI erythemal doses with multi-sensor ground-based measurements in Thessaloniki, Greece
}

Article

Accepted Version

Creative Commons: Attribution-Noncommercial-No Derivative Works 4.0

Zempila, M. M., Fountoulakis, I., Taylor, M., Kazadzis, S., Arola, A., Koukouli, M. E., Bais, A., Meleti, C. and Balis, D. (2018) Validation of OMI erythemal doses with multi-sensor ground-based measurements in Thessaloniki, Greece.

Atmospheric Environment, 183. pp. 106-121. ISSN 13522310 doi: https://doi.org/10.1016/j.atmosenv.2018.04.012 Available at https://centaur.reading.ac.uk/77161/

It is advisable to refer to the publisher's version if you intend to cite from the work. See Guidance on citing.

Published version at: http://dx.doi.org/10.1016/j.atmosenv.2018.04.012

To link to this article DOI: http://dx.doi.org/10.1016/j.atmosenv.2018.04.012

Publisher: Elsevier

All outputs in CentAUR are protected by Intellectual Property Rights law, including copyright law. Copyright and IPR is retained by the creators or other copyright holders. Terms and conditions for use of this material are defined in the End User Agreement. 


\section{CentAUR}

Central Archive at the University of Reading

Reading's research outputs online 


\section{Accepted Manuscript}

Validation of OMI erythemal doses with multi-sensor ground-based measurements in Thessaloniki, Greece

Melina Maria Zempila, Ilias Fountoulakis, Michael Taylor, Stelios Kazadzis, Antti Arola, Maria Elissavet Koukouli, Alkiviadis Bais, Chariklia Meleti, Dimitrios Balis

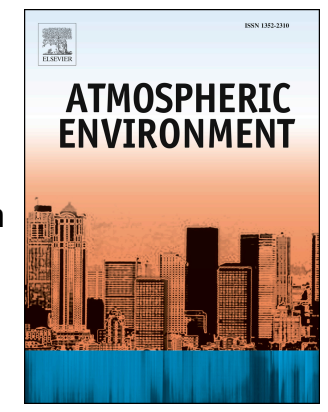

PII:

S1352-2310(18)30237-1

DOI:

10.1016/j.atmosenv.2018.04.012

Reference: $\quad$ AEA 15945

To appear in: Atmospheric Environment

Received Date: 12 December 2017

Revised Date: 3 April 2018

Accepted Date: 8 April 2018

Please cite this article as: Zempila, M.M., Fountoulakis, I., Taylor, M., Kazadzis, S., Arola, A., Koukouli, M.E., Bais, A., Meleti, C., Balis, D., Validation of OMI erythemal doses with multi-sensor groundbased measurements in Thessaloniki, Greece, Atmospheric Environment (2018), doi: 10.1016/ j.atmosenv.2018.04.012.

This is a PDF file of an unedited manuscript that has been accepted for publication. As a service to our customers we are providing this early version of the manuscript. The manuscript will undergo copyediting, typesetting, and review of the resulting proof before it is published in its final form. Please note that during the production process errors may be discovered which could affect the content, and all legal disclaimers that apply to the journal pertain. 
1 VALIDATION OF OMI ERYTHEMAL DOSES WITH MULTI-SENSOR GROUND-

BASED MEASUREMENTS IN THESSALONIKI, GREECE

*Correspondence author: melina.zempila@stfc.ac.uk Athens, Greece.

${ }^{(6)}$ Finnish Meteorological Institute, FI-70211 Kuopio, Finland.

\section{ABSTRACT}

The aim of this study is to validate the Ozone Monitoring Instrument (OMI) erythemal dose rates using ground-based measurements in Thessaloniki, Greece. In the Laboratory of Atmospheric Physics of the Aristotle University of Thessaloniki, a Yankee Environmental System UVB-1 radiometer measures the erythemal dose rates every minute, and a Norsk Institutt for Luftforskning (NILU) multi-filter radiometer provides multi-filter based irradiances that were used to derive erythemal dose rates for the period 2005-2014. Both these datasets were independently validated against collocated UV irradiance spectra from a Brewer MkIII spectrophotometer. Cloud detection was performed based on measurements of the global horizontal radiation from a Kipp \& Zonen pyranometer and from NILU measurements in the visible range. The satellite versus ground observation validation was performed taking into account the effect of temporal averaging, limitations related to OMI quality control criteria, cloud conditions, the solar zenith angle and atmospheric aerosol loading. Aerosol optical depth was also retrieved using a collocated CIMEL sunphotometer in order to assess its impact on the comparisons. The effect of total ozone columns 
satellite versus ground-based differences on the erythemal dose comparisons was also investigated.

34 Since most of the public awareness alerts are based on UV Index (UVI) classifications, an analysis and assessment of OMI capability for retrieving UVIs was also performed. An overestimation of the OMI erythemal product by $3-6 \%$ and $4-8 \%$ with respect to ground measurements is observed when examining overpass and noontime estimates respectively. The comparisons revealed a relatively small solar zenith angle dependence, with the OMI data showing a slight dependence on aerosol load, especially at high aerosol optical depth values. A mean underestimation of $2 \%$ in OMI total ozone columns under cloud-free conditions was found to lead

41 to an overestimation in OMI erythemal doses of $1-5 \%$. While OMI overestimated the erythemal 42 dose rates over the range of cloudiness conditions examined, its UVIs were found to be reliable for 43 the purpose of characterizing the ambient UV radiation impact.

\section{KEYWORDS}




\section{INTRODUCTION}

Changes in climate and atmospheric composition may lead to unprecedented changes in the Ultraviolet (UV) radiation that reaches the Earth's surface, raising the concern of indirect and direct effects to plants, ecosystems and humans (IPCC AR5, 2014; Tevini, 1993; WMO, 2007; WHO, 2008; Gao, Schmoldt, and Slusser, 2010; among others).Since 1982, when the ozone depletion was firstly observed (e.g. Farman et al., 1985; Bhartia et al., 1985), ground-based UV monitoring sites have been deployed at several locations all over the globe as a response to the raising concern of potential enhanced surface UV levels (Ghetti, Checcucci and Bornman, 2006). Most of these sites nowadays provide high frequency measurements for a variety of surface UV radiation products, such as the erythemal weighted dose rates, UV index, and so on. These data are used to validate model projections and satellite estimates, and to alert public awareness regarding the effects of the exposure to high solar UV radiation levels (Schmalwieser et al., 2002; Gies et al., 2004; Taskanen et al., 2007; Weihs et al., 2008; McKenzie et al., 2001; WHO, 2008; among others).

Up-to-date, space-borne UV product estimates originate from a variety of instruments onboard different platforms (Arola et al., 2002; Taskanen et al., 2006). One of them is the Ozone Monitoring Instrument (OMI) on board the Aura platform that provides estimates of surface erythemal dose rates and daily doses at overpass and noontime along with UV index (UVI) values since its launch in July 2004. Studies on OMI UV products (irradiances, erythemal doses and UV index) have reported differences of up to $30 \%$ or even higher under certain conditions overestimation in OMI UV products when compared with corresponding ground-based measurements, while these discrepancies were mainly observed at urban areas with higher aerosol loads (Kazadzis et al., 2009a; Kazadzis et al., 2009b; Ialongo et al., 2010; Antón et al. 2010; Cachorro et al., 2010; A Jebar et al., 2017). In 2009, a study by Arola et al. (2009) introduced a correction on the OMI data for absorbing aerosols which led to smaller discrepancies between OMI and ground-based data, with OMI performance being improved due to the imposed aerosol correction (Mateos et al., 2013; Muyimbwa et al., 2015; Cadet et al., 2017; Bernhard et al., 2015).

In this study, OMI UV erythemal dose rates and UVI values at overpass and local noontimes were thoroughly evaluated in Thessaloniki, Greece (lat: $40.69^{\circ} \mathrm{N}$, lon: $22.96^{\circ} \mathrm{E}$, alt: $60 \mathrm{~m}$ ) for the period 2005-2014, using a suite of ground-based instruments located at the Laboratory of Atmospheric Physics (LAP), at the Aristotle University of Thessaloniki, Greece together with retrieval models.

8 The influence of solar zenith angle (SZA), total ozone column (TOC) and aerosol optical depth (AOD) on the satellite UV products was also analysed, while the impact of three basic types of 
cloudiness conditions defined as: unstable cloudy (partially covered sun disk), stable cloudy (fully covered sun disk), and unoccluded sun disk, were also investigated.

Consequently, this study provides an innovative, complete and in-depth evaluation of the erythemal products provided by OMI/Aura, where the synergy of a wide suite of ground-based measurements is proven invaluable in order to examine, quantify and eventually unfold the dynamics of all the parameters potentially affecting the satellite retrievals.

The backbone of the paper is as follows. In Section 2 the ground-based instrumentation with the corresponding measurements are provided, while the OMI measurements are presented in the second subsection. In the following section (Section 3), the methodology applied to retrieve erythemal dose rates from irradiance measurements originating from the NILU-UV multi-filter radiometer is analysed, and the results are validated against collocated erythemal dose rate measurements from the UVB-1 radiometer placed also in the site. Then, the evaluation of the OMI erythemal dose rates is presented in Section 4, where the influence of the SZA, ozone, aerosols and cloudiness type is examined. At the end of the same section, the UV index comparisons are presented in order to elaborate on the ability of OMI UV Index estimations to serve as a public alert source, especially during the summer when the impact of the exposure to excess UV doses is more detrimental. The study concludes with its $5^{\text {th }}$ and final section by summarizing the main findings of the validation process.

\section{DATASETS AND INSTRUMENTATION}

\subsection{Ground-based measurements}

At the Laboratory of Atmospheric Physics at Aristotle University of Thessaloniki, Greece, (LAP/AUTh: http://lap.physics.auth.gr) three different types of solar radiation sensors provide estimates of erythemal dose rates continuously since 2005 as per the joint International Organisation for Standardisation and Commission Internationale de l' Éclairage standard ISO 17166:1999(E)/CIE S 007-1998 (and which we will abbreviate as 'CIE' here). For each instrument, different methods were applied in order to derive the erythemal dose rates, based on the characteristics of the measurements and the technical aspects of each instrument.

A Brewer MkIII spectrophotometer with serial number \#086 (B086) measures the UV solar spectrum (286.5 - $363 \mathrm{~nm}$ ) with a wavelength step of $0.5 \mathrm{~nm}$ at LAP since 1993. It is equipped with a double monochromator which is eliminating influences of stray light (scattered photons/signal at one wavelength that is affected by radiation from other wavelengths) in the measurements, thus 
112 providing better accuracy especially in the shorter UV wavelengths (Zerefos and Bais, 1997;

113 Karppinen et al., 2014). The uncertainty in the B086 spectra that are used in this study is 5\% for 114 wavelengths higher than $305 \mathrm{~nm}$ and solar zenith angles (SZA) smaller than $80^{\circ}$ (Fountoulakis et 115 al., 2016a), while low recorded signals at lower wavelengths and higher SZAs lead to higher 116 uncertainties in the measurements (Fountoulakis et al., 2016b; Gröbner et al., 2006). In order to 117 obtain solar spectra up to $400 \mathrm{~nm}$, the SHICrivm algorithm (Slaper et al., 1995) has been applied to 118 the original data, while the outcome was weighted with the erythemal dose action spectrum 119 (McKinlay \& Diffey, 1987) and integrated over the nominal wavelength range. Although B086 120 provides high accuracy erythemal dose rates, the frequency of the measurements is one every 20-40 121 minutes while a complete scan lasts $\sim 7$ minutes. Therefore, even though B086 scans cannot capture 122 high frequency changes in the radiation field, these measurements provide a unique tool to monitor 123 and assess the stability of other instruments that provide measurements with higher frequency 124 (Zempila et al., 2016a).

125 A Yankee Environmental System (YES) UVB-1 radiometer has also been operating since 1991. 126 The UVB-1 is a broadband instrument with a spectral response that simulates the erythemal action 127 spectrum proposed by McKinlay \& Diffey (1987) and thus provides erythemal dose measurements 128 on a 1-minute basis. Using libRadtran radiative transfer model simulations (Emde et al., 2015), look 129 up tables are calculated with respect to SZA and the TOC which are used to convert the UVB-1 130 measurements into erythemal irradiance due to differences between the actual and the desired 131 spectral response (Lantz \& Disterhoft, 1998; Webb et al., 2006;). The TOC values for these 132 corrections are obtained from collocated measurements from a second Brewer spectrophotometer 133 with serial number 005 (B005) (Meleti et al., 2012, Zerefos et al., 2002, Fragkos et al. 2014, 134 Fragkos et al. 2016). Under clear (cloudless) skies, the erythemal irradiances from B086 and UVB1351 (within one minute from the mean time of the B086 scan) have shown a satisfactory agreement; 136 within $4 \%(1 \sigma)$ for SZAs less than $80^{\circ}$ for the period $2004-2014$, that is in compliance with the 137 results presented in Hülsen et al. (2008). This agreement testifies that UVB-1 erythemal dose rates 138 have similar uncertainty level with the ones derived from B086 UV spectra (Garane et al., 2006; 139 Bais et al., 1996; Bais et al., 2001). Periodic intercalibrations of UVB-1 and B086 ensure the long140 term stability of the instrument.

141 A Norsk Institutt for Luftforskning (NILU)-UV multi-filter radiometer has been operational since 1422005 and forms part of the Greek UV network of NILU-UV radiometers (Kazantzidis et al., 2006). 143 The NILU-UV with serial number 04103 provides 1-minute measurements in 5 UV channels with 
nominal central wavelength at 302, 312, 320, 340 and $380 \mathrm{~nm}$ and a full width at half maximum (FWHM) of $10 \mathrm{~nm}$. The instrument is also equipped with an additional channel that measures the photosynthetically active radiation (PAR). In this study, measurements of the PAR channel were used to determine cloud-free cases based on the cloud detection algorithm proposed by Zempila et al., 2016b. By calibrating the NILU measurements with the B086 coincident irradiances, we estimate that the uncertainties of the NILU irradiance measurements used in this study are less than $5.5 \%$ (Zempila et al., 2016a). In Section 3 a description of the methodology used to derive erythemal dose rates from the NILU UV irradiances measurements is provided, while comparisons with UVB-1 measurements are presented in the second part of the section.

Additionally at LAP, a CM21 (Kipp\&Zonen) pyranometer provides global horizontal irradiance (GHI) measurements at one-minute intervals along with the corresponding standard deviation. Although the manufacturer states that the CM type of pyranometers have a stability of less than $\pm 0.5 \%$ /year, recalibration of the instrument that took place in 2005 revealed a high stability in its sensitivity with changes less than $0.1 \%$ during its 12 years of continuous operation (Bais et al., 2013). According to Zempila et al. (2016c) the maximum uncertainty inherent in the CM21 measurements is $6.4 \%$ based on error propagation techniques, while its records can provide information on the cloudiness status, distinguishing cases where the sun is unoccluded or fully/partially covered by clouds based on the methodology described by Vasaras et al. (2001). This information is used to further investigate the cloud effect on the satellite against ground-based erythemal dose rate comparisons.

Furthermore, a CE318-N Sun Sky photometer (CIMEL) provides atmospheric observations as part of the NASA aerosol robotic network (AERONET) (Holben et al., 1998; Balis et al., 2010). CIMEL provides AOD at the $340 \mathrm{~nm}$ wavelength, which is used to investigate the effect of aerosol variability over the station within the comparisons between the satellite- and ground-based erythemal data.

\subsection{Satellite measurements}

OMI is a contribution of the Netherlands's Agency for Aerospace Programs (NIVR) in collaboration with the Finnish Meteorological Institute (FMI) to the Earth Observing System (EOS) Aura platform. OMI is a nadir viewing hyperspectral imager capable of measuring the backscatter solar radiation in the UV and visible. With its high spectral resolution $(0.45 \mathrm{~nm}), \mathrm{OMI}$ is able to provide high accuracy estimations of several atmospheric parameters (Levelt et al., 2006). OMI scans in 740 
wavelength bands with a swath width of $2600 \mathrm{~km}$ that allows OMI to view the globe within one day (14 orbits). With its optimal $13 \times 24 \mathrm{~km}^{2}$ spatial resolution, OMI footprint centered to Thessaloniki coordinates, is covered by $50 \%$ of urban area while the city suburbs, rural area and the sea (with coverage of 25\%) occupy the rest half percentage. The OMI surface UV irradiance data include the erythemally-weighted daily doses and the dose rates both at the overpass time (mean Thessaloniki visiting time: 11:45 UT) and at the local solar noon (mean Thessaloniki local noon time: 10:26 UT). For this study, surface UV overpass data for Thessaloniki have been extracted from the NASA Aura Data Validation Centre for the period 2005-2014, http://avdc.gsfc.nasa.gov/. The OMI retrieval algorithm estimates the clear-sky surface irradiance using as inputs to radiative transfer model basic geophysical information, the measured total ozone column and climatological surface albedo (Torres et al., 2007 and references therein). Then, the clear-sky irradiances are adjusted to real scene values by a transmittance factor that is derived from the ratio of the backscattered radiance over the solar irradiances at $360 \mathrm{~nm}$ accounting for both clouds and scattering aerosols. Currently the UV algorithm uses a monthly aerosol climatology to also correct for absorbing aerosols (Arola et al., 2009). Regarding the cloud information, the radiative transfer model does not account for broken, multi-layer or mixed phase clouds resulting in more noisy comparisons with ground-based measurements under cloudy conditions. Furthermore, the derivation of the local noon values does not take into account changes in cloudiness, ozone and aerosols between local noon and overpass time, introducing higher uncertainty in the local noon retrievals (Torres et al., 2007). More details regarding the OMI UVB algorithm can be found in the Algorithm Theoretical Basis Document (Krotkov et al., 2002) and examples of its validation may be viewed in Tanskanen et al. (2007), Arola et al. (2009), and, specifically for Thessaloniki, in Kazadzis et al. (2009a; 2009b).

\section{The NILU-UV Erythemal product}

\subsection{Effective UV doses from NILU-UV irradiances using a neural network model}

To retrieve the effective UV dose rates from the original NILU irradiance measurements, a feedforward function-approximating neural network (NN) model (Hornik, Stinchcombe and White, 1989) was coded using MATLAB's object-oriented scripting language in conjunction with its Neural Network Toolbox (Beale, Hagan and Demuth, 2012). As inputs, the NN has NILU irradiance measurements at 302, 312, 320, 340 and $380 \mathrm{~nm}$ and various temporal variables (Kolehmainen, Martikainen and Ruuskanen, 2001) including the SZA, the day of the week (DOW) and the day of the year (DOY) and its sinusoidal components. The target (output) variable is the 
208 erythemal UV dose rate resulting from B086 erythemal weighted spectra.

209 From the available data, 47908 co-located input-output vectors were extracted to train and validate 210 the NN model. As per the NN method described in Zempila et al (2017b), the input and output 211 vectors were connected via 2 network layers - the first containing hidden neurons with hyperbolic 212 tangent (tanh) activation functions and the second containing linear activation functions. The NN 213 architecture was optimized following the method of Taylor et al (2014) where the number of hidden 214 neurons was varied from 5 to 15 and the proportion of training data used in NN learning was varied 215 from $50 \%$ to $95 \%$ in steps of $5 \%$ with a mean squared error (MSE) cost function measuring the 216 difference in $\mathrm{NN}$ retrievals and target erythemal dose rates for 100 different $\mathrm{NN}$ architectures. The optimal NN has a training proportion of $90 \%$ and 13 hidden neurons and used the same NN learning scheme based on Bayesian regularization back-propagation described in Zempila et al (2017b). In Error! Reference source not found.the range of the validity of the trained optimal NN is provided based on the input data range of the subset used to train the model. The addition temporal variables are not listed as they have the standard ranges (see Zempila et al (2017b) for details).

Table 1. Range of validity of the trained optimal NN as determined by its input parameters (upper list) and output parameters (lower list).

\begin{tabular}{lllll}
\hline Parameter & Min & Max & Mean & St. Dev. \\
\hline $\operatorname{Ir}(305)\left(\mathrm{W} / \mathrm{m}^{2} / \mathrm{nm}\right)$ & 0 & 0.017 & 0.003 & 0.004 \\
\hline $\operatorname{Ir}(312)\left(\mathrm{W} / \mathrm{m}^{2} / \mathrm{nm}\right)$ & 0 & 0.229 & 0.064 & 0.055 \\
\hline $\operatorname{Ir}(320)\left(\mathrm{W} / \mathrm{m}^{2} / \mathrm{nm}\right)$ & 0 & 0.333 & 0.108 & 0.079 \\
\hline $\operatorname{Ir}(340)\left(\mathrm{W} / \mathrm{m}^{2} / \mathrm{nm}\right)$ & 0 & 0.678 & 0.252 & 0.159 \\
\hline $\operatorname{Ir}(380)\left(\mathrm{W} / \mathrm{m}^{2} / \mathrm{nm}\right)$ & 0 & 0.871 & 0.327 & 0.208 \\
\hline $\mathrm{SZA}($ Degrees $)$ & 15.63 & 81.162 & 54.373 & 16.120 \\
\hline Erythemal dose rate $\left(\mathrm{W} / \mathrm{m}^{2}\right)$ & 0 & 0.234 & 0.056 & 0.054
\end{tabular}

226 Following the approach of Zempila et al (2017b), the trained and validated NN was then run in unsupervised mode using the full record of available coincident NILU irradiances (2.47 million cases) to extract all vectors closest to local noon and within \pm 30 minutes of the satellite overpass 229 time.

230 To calculate the uncertainty of the neural-network-based estimates of the retrieved erythemal dose 231 rates, the median absolute percentage error (MAPE) was calculated for the differences between the 232 NN estimates and the target values. Based on this statistical measure, we calculate that the 
233 uncertainty of the $\mathrm{NN}$ in the dose rates was 3.6\%, which is within the level of uncertainty of both

234 NILU and B086 irradiances which are 5.6\% and 5\% respectively. Taking the higher NILU

235 uncertainty as an upper bound on the radiance uncertainty and combining this in quadrature with the

236 NN uncertainty, we estimate the overall uncertainty on the NILU NN erythemal dose rate retrievals 237 to be $6.5 \%$.

\section{$238 \quad$ 3.2.Comparisons of NILU-UV and UVB-1 erythemal data}

239 To further verify the validity of the NILU NN erythemal retrievals, comparisons with the collocated 240 UVB-1 measurements were performed as an independent source of information. For these 241 comparisons, 1-minute synchronous NILU and UVB-1 data were used, while hourly mean values were calculated in order to eliminate the influence of any possible time shifts and random incidences (e.g. temporarily shading of the input optics) into the datasets. Additionally, hourly data with more than $70 \%$ abundance in cloud-free minute measurements, as identified from the NILU PAR algorithm (Zempila et al., 2016b), were characterized as "NILU clear skies".

In Figure 1 the relative percentage differences between OMI and UVB-1 are presented for all and cloud-free sky cases respectively. Although the distribution of the relative percentage differences is normal, we provide the median and the 20-80 percentile values as measures of statistical differences.
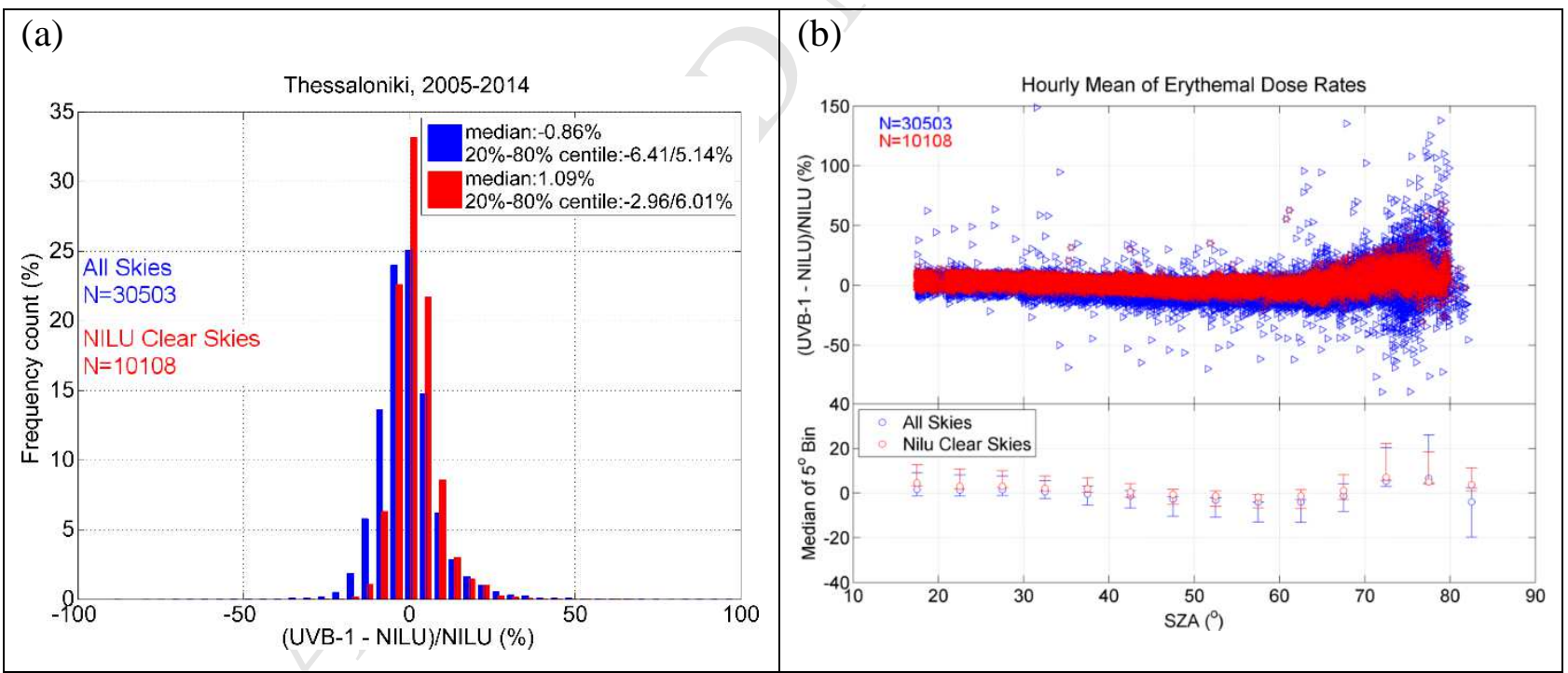

Figure 1 (a) Histogram of the relative percentage differences of hourly mean values for the NILU and UVB-1 erythemal dose rates. Cases were more than $\mathbf{7 0 \%}$ of the data were identified as cloud-free based on NILU PAR measurements, are indicated in red. The median and $20 / 80$ percentiles are also presented. (b) The SZA dependence of the relative percentage differences is also depicted, along with the median percentage differences of $5^{\circ} \mathrm{SZA}$ bins. The error bars in the lower panel refer to the 20/80 percentile values.

As seen in Figure 1 (a), the overall conformity between the two ground-based datasets was quite 
good with small median differences, $-0.86 \%$ and $1.09 \%$ for all and cloud-free skies respectively, on

257 a large number of coincidences (30506 for all skies, and 10108 for the NILU-based cloud free instances, as shown in Figure 1). Low values of the 20/80 percentiles were found within the uncertainty of both data sets; this shows that both time series result in comparable values.

To elaborate more on these comparisons, the influence of the SZA was also investigated (Figure 1(b)). It was found that for SZAs less than $70^{\circ}$ under cloud-free conditions the relative percentage differences resulted to a median of $0.45 \%$ with corresponding $20 / 80$ percentiles of $-3.25 \% / 4.60 \%$ respectively. Furthermore, the SZA pattern seen in Figure 1(b) can be attributed to the different geometry of the input optics, differences in angular responses and calibration procedures applied to each dataset. For SZAs $>70^{\circ}$ we observe larger scatter for both cloudless and clear sky cases as an impact of the non-ideal angular response of both instrument and the increasing signal to noise ratio. Summarizing, the comparisons of the NILU NN erythemal hourly doses revealed a good agreement with the collocated UVB-1 measurements. Therefore, the NILU NN erythemal data represent a valid dataset, with denoted uncertainty of $6.5 \%$ that is comparable with the uncertainty of the UVB-

\section{Evaluation of OMI /Aura erythemal product}

In the following section, comparisons among the OMI and theNILU, UVB-1 and B086 erythemal data were performed. The OMI/Aura NASA algorithm provides erythemal dose rates at overpass time (measurement) as well as at local noon (interpolated). Both cases were investigated, while at the same time identification of cloud-free cases took place in two different ways: i) a cloud screening algorithm based on NILU-PAR measurements was used to define the NILU clear sky cases (NILU clear skies), according to Zempila et al., 2016b, and ii) the limitation of Lambertian equivalent reflectivity (LER) at $360 \mathrm{~nm}$ less than 0.1 was applied to satellite estimates in order to derive the satellite cloudless cases (OMI clear skies), according to Antón et al., 2010. Since most of the relevant studies use average values of 1 hour $( \pm 30 \mathrm{~min})$ around the overpass time of the satellite (e.g. Chubarova et al,, 2002), compensating in this way for moving clouds within the OMI pixel, the same statistics were recalculated for the 1 hour averaging as well. For the identification of the NILU cloud-free 1-hour averages, data within this timeframe with more than $70 \%$ cloud-free 1minute measurements were characterized as hourly averages under clear skies (NILU clear skies). For the OMI clear skies, the same criterion, as above, was used (LER<0.1). In Table 3 we present a statistical summary of the comparisons performed for the overpass and local noontime, based on 
288 both temporal matching approaches. For all comparisons, only satellite data within a radius of 50

$289 \mathrm{~km}$ were taken into account, while comparisons within $\pm 150 \%$ were analysed to avoid including 290 erratic data (e.g. random drop of signal due to obscured ground sensor) into the statistics. The later 291 limitation ended to a $2.5 \%$ and $2.7 \%$ reduction of the original OMI/NILU and OMI/UVB-1 exact 292 overpass datasets respectively, while the reduction in the 1-hour overpass comparisons was $1.5 \%$ 293 for both OMI/NILU and OMI/UVB-1 comparisons. For the local noon comparisons, both 294 OMI/NILU and OMI/UVB-1 are reduced by $2.5 \%$ for the exact coincidences when limiting the 295 dataset within the range of $\pm 150 \%$, while this limitation reduced the amount of coincidences of the 296 1-hour averages around local noon by $1.7 \%$ for both the two types of the ground-based instruments. 297 An overview of the backbone of this section is presented in Table2 and Flow Chart 1, to facilitate 298 the readers.

300 Table2. Overview of the measurement characteristics and datasets used in this study for the period 301 2005-2014 over Thessaloniki, Greece (lat: $40.69^{\circ} \mathrm{N}$, lon: $22.96^{\circ} \mathrm{E}$, alt: $60 \mathrm{~m}$ ).

\begin{tabular}{|c|c|c|c|c|}
\hline Instrument & $\begin{array}{l}\text { Recording } \\
\text { Frequency }\end{array}$ & $\begin{array}{l}\text { Original } \\
\text { Measurements }\end{array}$ & Derived Data & Cloud Information \\
\hline Ground-based & & 2 & & \\
\hline NILU-UV & 1-min & $\begin{array}{l}\text { Irradiances at } 5 \\
\mathrm{Wv}\left[\mathrm{W} / \mathrm{m}^{2} / \mathrm{nm}\right] \\
\operatorname{PAR}\left[\mathrm{W} / \mathrm{m}^{2}\right]\end{array}$ & $\begin{array}{l}\text { Erythemal dose rates } \\
{\left[\mathrm{W} / \mathrm{m}^{2}\right]} \\
\text { Cloud binary } \\
\text { information }\end{array}$ & $\begin{array}{l}\text { YES } \\
\text { [using the PAR data] }\end{array}$ \\
\hline UVB-1 & 1-min & $\begin{array}{l}\text { Erythemal dose rates } \\
{\left[\mathrm{W} / \mathrm{m}^{2}\right]}\end{array}$ & $\begin{array}{l}\text { Erythemal dose rates } \\
{\left[\mathrm{W} / \mathrm{m}^{2}\right]}\end{array}$ & NO \\
\hline B086 & $20-40 \mathrm{~min}$ & $\begin{array}{l}\text { Spectral irradiances } \\
{\left[\mathrm{W} / \mathrm{m}^{2} / \mathrm{nm}\right]}\end{array}$ & $\begin{array}{l}\text { Erythemal dose rates } \\
{\left[\mathrm{W} / \mathrm{m}^{2}\right]}\end{array}$ & NO \\
\hline CM21 & 1-min & $\begin{array}{l}\text { Solar radiation } \\
{\left[\mathrm{W} / \mathrm{m}^{2}\right]}\end{array}$ & $\begin{array}{l}\text { Cloudiness } \\
\text { information }\end{array}$ & YES \\
\hline CIMEL & $\geq 15$-min & unitless & AOD@340nm & Cloud free cases \\
\hline \multicolumn{5}{|l|}{ Spaceborne } \\
\hline OMI & Daily & $\begin{array}{l}\text { Erythemal dose rates } \\
{\left[\mathrm{W} / \mathrm{m}^{2}\right]}\end{array}$ & $\begin{array}{l}\text { Erythemal dose rates } \\
{\left[\mathrm{W} / \mathrm{m}^{2}\right]}\end{array}$ & YES \\
\hline
\end{tabular}




\section{Data Inventory}

\section{Ground}

\section{Spaceborne}
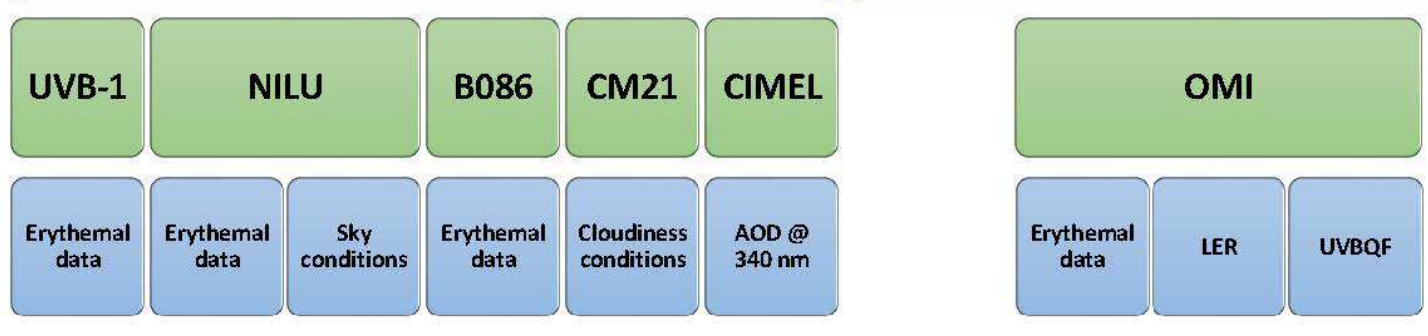

\section{Validation Study}

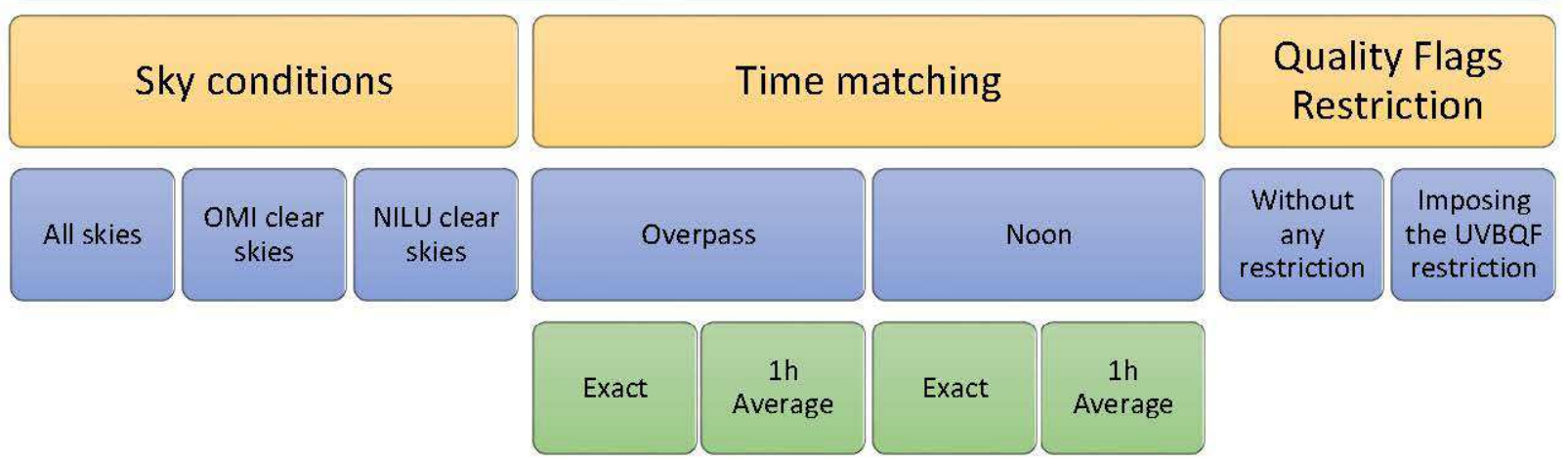

\section{Dependecies Study}

Flow Chart 1. Overview of the data inventory used in this study, along with a short description of the schematic of the validation and dependency studies performed between the ground- and satellite-based erythemal data.

The comparison statistics are presented in the form of median and 20/80 percentile values since the dataset cannot be represented with a normal distribution because the comparisons showed a persistent tendency towards higher relative percentage differences. In Table 3, for all skies at the exact overpass time, the agreement between the NILU and OMI erythemal dose rates is $2.5 \%$ while the satellite overestimates by $4.1 \%$ at local noon, with a percentile range (80\%-20\%) of $24 \%$ and

311 11.2\% respectively. Limiting the dataset to cloud-free cases based on OMI observations leads to 
312 higher relative percentage differences, $4.0 \%$ for the overpass and 5.8\% for the local noontime, with 313 the 20/80 percentile difference ranging between 11-12\%. For the overpass comparisons, although 314 the median of the relative percentage differences seen under the NILU defined clear days is less 315 than the one referring to OMI clear skies cases, the later one presented lower scatter based on the 316 observed 20/80 percentiles. This was also the case when examining the noon values, where the 317 scatter seems to be marginally larger for the NILU clear results. The larger scatter in the noon 318 comparisons under all sky cases can be attributed to differences in the model/algorithm estimations 319 and differences in the geometry and type of the two sensors, since the OMI noontime values are 320 calculated through time extrapolation using the overpass time and assuming similar atmospheric 321 (cloud) conditions. Although the cloud-free cases result in lower amount of coincidences, the 322 median differences observed in OMI/NILU comparisons imply that the agreement of the OMI 323 erythemal dose rates is equally good under all-sky conditions as it is for the cloud-free cases.

Table 3. Statistical analysis of the differences between erythemal dose rates provided by OMI/Aura and NILU/UVB-1/B086 for the exact overpass and local noontime coincidences. OMI/AURA data are provided within a radius of $50 \mathrm{~km}$ from the site location. Differences with absolute values more than $150 \%$ were eliminated.

\section{Overpass}

\begin{tabular}{lllllll}
\hline (OMI-NILU)/NILU & All Skies & \multicolumn{2}{l}{ OMI Clear } & NILU Clear & All Skies & \multicolumn{2}{l}{ OMI Clear } & NILU Clear \\
\hline \hline N counts & 2013 & 691 & 761 & 2267 & 740 & 915 \\
\hline Median (\%) & 2.5 & 4.0 & 2.1 & 4.1 & 5.8 & 3.2 \\
\hline 20/80 percentiles (\%) $-8.5 / 15.5$ & $-1.1 / 10.0$ & $-4.7 / 8.4$ & $-7.1 / 21.1$ & $0.8 / 11.8$ & $-4.4 / 9.4$ \\
\hline
\end{tabular}

\section{(OMI-UVB1)/UVB1}

\begin{tabular}{lllllll}
\hline \hline N counts & 2009 & 691 & 761 & 2269 & 740 & 915 \\
\hline Median (\%) & 3.9 & 4.0 & 2.0 & 5.3 & 5.0 & 2.2 \\
\hline 20/80 percentiles (\%) & $-7.7 / 22.5$ & $-3.3 / 13.0$ & $-6.1 / 10.3$ & $-7.4 / 28.2$ & $-1.9 / 14.7$ & $-7.5 / 10$ \\
\hline (OMI-B086)/B086 & 43 & 14 & 18 & 162 & 63 & 69 \\
\hline \hline N counts & 4.5 & 4.7 & 4.4 & 4.9 & 6.3 & 2.9 \\
\hline Median (\%) & & & & & \\
\hline 20/80 percentiles (\%) & $-2.5 / 20.4$ & $3.9 / 13.4$ & $0.0 / 9.4$ & $-4.8 / 16.7$ & $-0.2 / 12.8$ & $-4.4 / 10.4$
\end{tabular}


329 Similarly, the OMI/UVB-1 comparisons revealed an agreement of 3.9\% for the all skies cases 330 during the overpass time, which is slightly improved at $2 \%$ under the NILU defined clear cases, 331 while it remained unaltered at $4 \%$ for the OMI cloud-free limited dataset. The number of 332 coincidences was the same as for the OMI/NILU comparisons for both OMI and NILU cloudless 333 days. When analysing the local noon exact matching, the percentage differences were increased to $3345.3 \%, 5.0 \%$ and $2.2 \%$ for all, OMI clear and NILU clear skies, and the number of coincidences was 335 also increased to 2269, 740 and 915 respectively. In general, the comparisons between OMI and 336 UVB-1 data at the exact overpass result in similar median differences with the OMI/NILU comparisons, but the denoted percentile ranges are higher than the later ones. This aspect could be an indicator on the uncertainty of the UVB- 1 erythemal dose rates, especially for high SZAs since they are not corrected for the non-ideal angular response of the instrument.

340 OMI/B086 comparisons result in extremely few collocations for the exact overpass minute (43 for 341 the all skies cases), thus the statistical significance of the results is considered low, although the 342 percentages are not different from those of the OMI/NILU and OMI/UVB-1 differences. The low 343 number of coincidences during the satellite overpass is expected since B086 performs sky scans 344 within steps of 20 up to 40 minutes apart, making the existence of coincident overpass 345 measurements statistically rare. When checking the local noon exact coincidences, the number of 346 paired satellite and B086 data is almost quadrupled, 162, 63 and 69 for all skies, OMI clear skies 347 and NILU clear skies respectively, but still small to deduce a solid conclusion. It is though 348 reassuring that the results are similar to the ones obtained from the other comparisons, and as seen

349 in Table 3, for all cases and all comparisons, the NILU clear skies incidences provide the smallest 350 median value of the relative percentage differences, providing an additional means of verification of 351 the accuracy of the NILU data.

Table 4. Statistical analysis of the differences between erythemal dose rates provided by OMI/Aura 354 and NILU/UVB-1/B086 for the 1-hour average values around the OMI overpass and local noontime 355 ( \pm 30 minute). OMI/AURA data are provided within a radius of $50 \mathrm{~km}$ from the site location. 356 Differences with absolute values more than $150 \%$ were eliminated.

1h around Overpass (OMI-NILU)/NILU All Skies OMI Clear NILU Clear All Skies

$\mathrm{N}$ counts 2300
756 735 1h around Local Noon

OMI Clear NILU Clear

755
774 


\begin{tabular}{lllllll}
\hline Median (\%) & 3.9 & 4.8 & 2.8 & 5.6 & 6.6 & 4.6 \\
\hline $20 / 80$ percentiles (\%) & $-5.3 / 16.5$ & $0.0 / 11.1$ & $-3 / 8.6$ & $-4.7 / 19.5$ & $1.4 / 12.7$ & $-1.8 / 10.4$ \\
\hline
\end{tabular}

(OMI-UVB1)/UVB1

\begin{tabular}{lllllll}
\hline \hline N counts & 2300 & 756 & 735 & 2299 & 755 & 774 \\
\hline Median (\%) & 5.9 & 5.1 & 2.7 & 6.6 & 6.0 & 3.2 \\
\hline 20/80 percentiles (\%) & $-4.9 / 22.8$ & $-2.1 / 13.8$ & $-5.1 / 10.3$ & $-4.8 / 26.6$ & $-0.9 / 15.3$ & $-5.0 / 11.1$ \\
\hline
\end{tabular}

(OMI-B086)/B086

\begin{tabular}{lllllll}
\hline \hline N counts & 1751 & 572 & 558 & 1448 & 485 & 523 \\
\hline Median (\%) & 6.9 & 7.1 & 4.6 & 5.2 & 6.1 & 3.7 \\
\hline 20/80 percentiles (\%) & $-4.3 / 25.6$ & $0.0 / 14.8$ & $-2.9 / 12.2$ & $-5.3 / 24.0$ & $0.7 / 13.4$ & $-1.7 / 11.1$ \\
\hline
\end{tabular}

When examining the 1-hour averaged values in Table 4, in all cases, apart from the B086 dataset (1751 coincidences instead of 1448 for all skies, 572 instead of 485 for the OMI clear skies and 558 instead of 523 for the NILU cloud-free cases at the overpass and local noon respectively), the number of coincidences were similar between the 1 hour data around the overpass and the local noon. The median differences tend to show an enhanced overestimation by OMI for all cases (1h around overpass and local noon), for all and clear sky conditions, when compared to the exact time coincidences. On the other hand, the 20/80 percentile range seemed to be little affected by the temporal averaging of ground-based data, with the comparisons for the 1-hour averaged values to correspond in slightly smaller percentile ranges ( 20\%), again with the clear skies cases presenting the smaller range (12\%-15\%). As seen in the table, the 1-hour averaging favoured the number of coincidences under all skies cases in all comparisons with the ground-based instruments.

369 Furthermore, the temporal averaging ended to smaller percentile ranges in most of the cases for 370 both, exact and local noon, time matching. On the other hand, the median differences were slightly 371 higher since OMI sees the pixel area at the exact overpass time, while the characterization of NILU 372 cloud-free cases within 1 hour can result to different outcomes based on the limitation set on the 1373 minute cloud-free cases (in our case a 70\% abundance of cloud-free minute points was applied). 374 Therefore, careful consideration of all available choices should take place based on the available 375 data and the scope of each study, since exact overpass match and time averaging present their own benefits, while also introduce certain limitations. 
To further investigate the accuracy of the OMI erythemal dose rates and since the OMI dataset also provides additional information regarding the Quality Flags on Pixel Level (UVBQF), an analysis on limiting OMI dataset based on the UVBQF was also performed. This 16 digits binary flag elaborates on special characteristics for the quality of the OMI retrieved data and the input information used in the satellite retrieval algorithm. For the UVBQF limitation, the usage of the TOMS $380 \mathrm{~nm}$ monthly LER (MLER) climatology (Herman and Celarier, 1997) and the usage of the moving time-window (MTW) climatology (Tanskanen et al. 2003) were permitted for the surface albedo, along with the application of the aerosol correction. Again the exact overpass and local noontime were examined (Table 5), while the potential of any improvement on the comparisons by a time averaging, was also analysed in Table 6.

Table 5 Statistical analysis of the differences between erythemal dose rates provided by OMI/Aura and NILU/UVB-1/B086 for the exact overpass and local noontime coincidences when restrictions on the UVBQFlags were imposed. Differences with absolute value more than $150 \%$ were eliminated.

\section{UVBQF Limited Overpass}

\section{Local Noon}

(OMI-NILU)/NILU All Skies OMI Clear NILU Clear All Skies OMI Clear NILU Clear

\begin{tabular}{lllllll}
\hline \hline N counts & 947 & 277 & 322 & 1121 & 310 & 381 \\
\hline Median (\%) & 3.0 & 4.7 & 4.6 & 4.9 & 6.3 & 3.2 \\
\hline 20/80 percentiles (\%) $-8.6 / 17.7$ & $-1.0 / 11.3$ & $-5.1 / 8.4$ & $-7.3 / 24.6$ & $1.3 / 13.2$ & $-3.8 / 9.7$ \\
\hline
\end{tabular}

(OMI-UVB1)/UVB1

\begin{tabular}{lllllll}
\hline \hline N counts & 948 & 277 & 322 & 1122 & 310 & 381 \\
\hline Median (\%) & 5.1 & 4.5 & 2.0 & 6.8 & 6.1 & 2.2 \\
\hline 20/80 percentiles $(\%)$ & $-6.8 / 23.2$ & $-2.7 / 13.9$ & $-5.9 / 9.6$ & $-6.4 / 32.1$ & $-1.0 / 16.6$ & $-6.2 / 9.8$ \\
\hline
\end{tabular}

(OMI-B086)/B086

\begin{tabular}{lllllll}
\hline \hline N counts & 20 & 4 & 6 & 96 & 31 & 34 \\
\hline Median (\%) & 5.2 & 9.0 & 2.4 & 4.2 & 9.3 & 0.2 \\
\hline 20/80 percentiles (\%) & $-1.2 / 38.2$ & $1.3 / 15.1$ & $-0.7 / 6.0$ & $-7.0 / 15.4$ & $-0.4 / 12.9$ & $-9.4 / 9.8$ \\
\hline
\end{tabular}


satellite- and ground-based data, while the UVBQF limitation results in a significant reduction of the original coincidences. The quality flag that produced almost $36 \%$ reduction of the original OMI dataset under all skies was the second in order UVBQF flag, which refers to data retrieved under suspicious inputs into the radiative transfer model. For the limited dataset, the observed median differences under all skies conditions denoted that the OMI local noon data, exact and 1-hour averages, overestimate the NILU erythemal slightly more, by $4.9 \%$ and $5.8 \%$ respectively, when compared with the values at the exact and 1-hour averages at the satellite overpass time (3.0\% and $3.9 \%$ respectively). The same pattern was observed for the OMI/UVB-1 comparisons, though the overestimation of the OMI data was found to be $5.1 \%$ and $6.4 \%$ for the exact and 1 -hour averages at the overpass time, compared to the respective $6.8 \%$ and $7.5 \%$ median differences of the noontime. In general, the 20/80 percentile ranges are larger for the noontime values when compared with the ones at the overpass for both NILU/UVB-1 and OMI comparisons (31.9\% for the NILU and 38.5\% for the UVB-1), while the 1-hour mean values end to smaller range due to the time averaging, $27.2 \%$ and $34.3 \%$ respectively. Again, the 1-hour time averaging resulted in higher overestimation in OMI retrieved erythemal dose rates, while it favoured the number of the paired satellite and ground-based data. The percentile range was smaller for the time averaging case, meaning that the compared data, OMI and NILU/UVB-1, presented less scattering that those that resulted from the exact matching with imposing the UVBQF limitation. Since the UVBQF limitations did not

412 improve the comparison statistics and reduced significantly the number of coincidences on the exact 413 overpass, the application of such limitation should be carefully considered especially in cases where 414 the original dataset is limited in number.

Table 6. Statistical analysis of the differences between erythemal dose rates provided by OMI/Aura 417 and NILU/UVB-1/B086 the 1-hour averaged values around the OMI overpass and local noontime 418 ( \pm 30 minute). Differences with absolute value more than $150 \%$ were eliminated.

UVBQF Limited 1h around Overpass 1h around Local Noon

(OMI-NILU)/NILU All Skies OMI Clear NILU Clear All Skies OMI Clear NILU Clear

\begin{tabular}{lllllll}
\hline \hline N counts & 1131 & 312 & 315 & 1151 & 315 & 332 \\
\hline Median (\%) & 3.9 & 5.5 & 2.3 & 5.8 & 7.1 & 4.5 \\
\hline $20 / 80$ percentiles (\%) & $-5.3 / 17$ & $0.0 / 12.1$ & $-4.2 / 8.8$ & $-5.4 / 21.8$ & $1.5 / 13.6$ & $-2.6 / 10.9$ \\
\hline
\end{tabular}




\begin{tabular}{lllllll}
\hline N counts & 1132 & 312 & 315 & 1152 & 315 & 332 \\
\hline Median (\%) & 6.4 & 6.1 & 1.9 & 7.5 & 6.6 & 3.1 \\
\hline 20/80 percentiles (\%) & $-4.8 / 24.6$ & $-1.3 / 14.3$ & $-5.1 / 9.6$ & $-4.7 / 29.6$ & $-0.1 / 16.6$ & $-5.5 / 11.3$ \\
\hline
\end{tabular}

\section{(OMI-B086)/B086}

\begin{tabular}{lllllll}
\hline \hline N counts & 857 & 248 & 241 & 708 & 206 & 223 \\
\hline Median (\%) & 7.9 & 8.3 & 4.7 & 5.6 & 6.8 & 3.7 \\
\hline 20/80 percentiles (\%) & $-4.8 / 26.1$ & $0.3 / 16.8$ & $-3.0 / 13.1$ & $-6.5 / 27.0$ & $1.1 / 13.6$ & $-2.1 / 11.2$ \\
\hline
\end{tabular}

For the cloud-free cases identified by OMI, the median value at the exact overpass was equal to $4.7 \%$, while at the local noon the corresponding value is $6.3 \%$. These numbers were slightly 422 improved to $4.5 \%$ and $6.1 \%$ for the UVB-1 comparisons. A similar behaviour was detected for the 423 1-hour average comparisons for the OMI clear cases, where the overestimation of the satellite 424 against NILU retrieved dose rates was $5.5 \%$ for the overpass and $7.1 \%$ for the local noon. The 425 corresponding values for the UVB-1 data were $6.1 \%$ and $6.6 \%$. When imposing the cloudiness 426 characterization, the scatter of the coupled OMI/NILU data at the overpass, which is presented in 427 the 20/80 percentile form, was restrained to $-1.0 \% / 11.3 \%$ for the OMI clear cases to $-5.1 \% / 8.4 \%$ for 428 the NILU clear cases for the exact matching. However, the time averaging did not improve much 429 the interquartile range in the OMI/NILU comparisons.

430 Regarding the OMI/UVB-1 results, again the NILU defined clear cases resulted to lower median 431 differences and scattering for both overpass and local noontime exact time matching. The averaging 432 around the overpass time, similarly to the OMI/NILU comparisons, resulted to slightly higher 433 median values of the relative percentage differences, whereas the interquartile range of the results 434 was not improved drastically.

435 Although the OMI/B086 comparisons resulted in a smaller sample size, especially during the exact 436 time matching, the comparison results were in agreement with the comparison results using NILU 437 and UVB-1 data.

439 Based on these findings, we can conclude that imposing the UVBQF limitation to the original OMI 440 dataset did not significantly improve the comparison results. The number of coincident ground- and 441 satellite-based data was significantly reduced in all tested cases under the imposed limitation, while 442 the 1-hour averaging with UVBQF imposed limitations favoured the number of coincidences 
443 between OMI and NILU/UVB-1 data when compared with the exact time matching. Similarly to 444 previous findings, the scattering of the comparisons was generally less when applying the 1-hour 445 time averaging, but the overestimation of OMI was a bit higher for this case.

447 Summarizing, no significant deviations between the correlation statistics were seen in all tested 448 combinations: exact overpass, exact local noon, 1-hour averages around the exact overpass and 449 local noon, and the implementation of the UVBQF limitation on all previous combinations. 450 Although cloud-free cases resulted in better correlation statistics, the all sky cases also presented 451 low median differences as well, while the scattering of the comparisons was higher under all 452 cloudiness conditions, as expected. In general, an overestimation of the OMI erythemal product by $4533-6 \%$ on average is expected when examining the overpass comparisons. For the noontime 454 estimations, OMI seems to overestimate by $4-8 \%$. Since the overpass time and the local noontime 455 do not match (the mean visiting time over Thessaloniki is 11:45 UT, while the local noon is at 456 10:26 $\pm 10 \mathrm{UT})$, the noontime values are in practice projections of the overpass time values through 457 model simulations based on the overpass atmospheric constituent retrievals, which can introduce 458 higher uncertainty levels in the OMI retrievals.

460 To visualize the findings of the discussion above, normalized Taylor diagrams (Taylor, 2001) of the 461 1-hour averages for each ground-based time series were produced for the overpass and noontime for 462 all skies, NILU clear skies, and OMI clear skies without taking into account the UVBQF limitation 463 that would lead to lower number of coincidences. OMI time series statistics were used as the 464 reference dataset (black reference dot/line on Figure 2) for the shake of comparability between the 465 different ground-based instruments. 


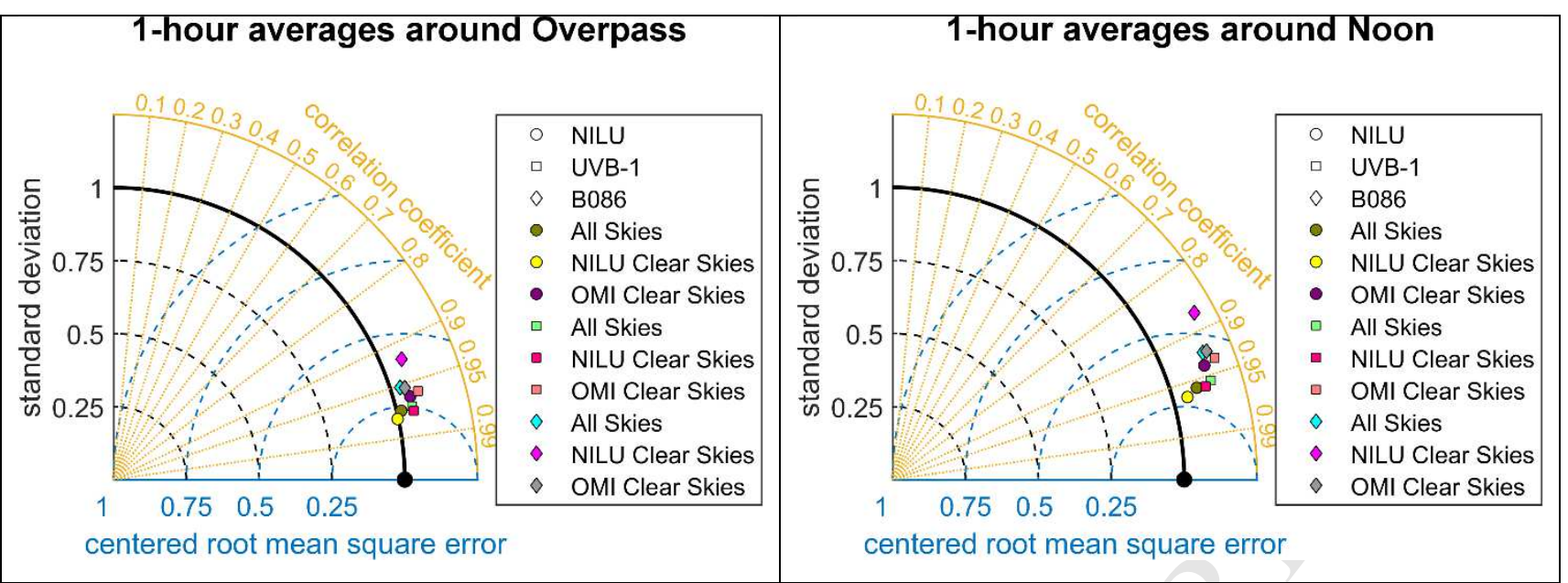

Figure 2 Normalized Taylor diagrams between OMI and NILU, UVB-1 and B086 erythemal dose rates for the 1-hour time matching choice around overpass (left panel) and around noontime (right panel). OMI erythemal data were used as the reference dataset (black dot on the diagrams), while the statistics of NILU data are presented as circles, UVB-1 data as squares and B086 data as diamonds. The colours represent the cloudiness constriction imposed on each ground-based dataset. Both standard deviations and centered root mean square errors were normalized to the standard deviation of the reference dataset.

For the overpass comparisons in Figure 2 (left panel), both NILU and UVB-1 data under all cloudiness conditions, showed high correlation coefficients $(>0.95)$ when compared with the corresponding OMI dataset, while the standard deviations for most of the ground-based data were found to be slightly higher than that of the OMI dataset, apart for the NILU data under the NILU clear sky restriction. The centered root mean square error (CRMSE) is a means of measuring the difference between the two compared datasets neglecting any observed bias between the two of them. For the overpass comparisons, the normalized CRMSE ranged between 0.21 (for the OMI/NILU comparison under NILU defined cloud free cases) and 0.41 (for the OMI/B086 comparison again under NILU defined cloud free cases).

For the noon comparisons provided also in Figure 2 (right panel), again the observed correlation coefficients (R) ranged between 0.94 and 0.96 apart for the comparisons performed for the OMI/B086 datasets ( $\mathrm{R}=0.93$ for all skies and OMI clear skies, $\mathrm{R}=0.88$ for NILU clear skies). In all cases the normalized standard deviation was higher than the corresponding in the overpass comparisons, denoting that for the noontime comparisons the ground-based data revealed higher variability that the one corresponding to OMI noon values. Similarly, the CRMSE values were higher than the ones for the overpass comparisons (0.21-0.41) further supporting the findings in Table 3.

Based on these summary comments, we can conclude that each comparison scheme can be used to serve specific purposes based on the scope of each study with equally well representation of the 
statistical results. Overpass coincidences were proved to present better statistical results, since OMI measurements are taken at that particular time, while 1-hour averages of ground-based data around overpass time provided larger number of paired satellite- and ground-based erythemal data. Cloudfree cases, defined by the NILU PAR algorithm, provide a stricter limitation than OMI defined clear cases where the upper limit of LER $<0.1$ might result in clouds present within the OMI pixel. Users should also take into account the size of the final dataset, since as already discussed, specific limitations (cloudless skies, UVBQF limitation, limited BREWER datasets) can significantly reduce the amount of the paired satellite and ground data.

Since the differences between satellite and ground data are influenced by a set of parameters, like SZA, cloud optical thickness, ozone and AOD, in the following sections a thorough analysis is performed hoping to locate the main source of the observed discrepancies. For this evaluation, both exact and 1-hour averages around the overpass time were utilized, while the UVBQF limitation was not applied to avoid ending with a low number of coincidences.

\subsection{The SZA dependence}

For aerosol and cloud-free scenes and non-snow/ice surfaces the accuracy of the OMI erythemal dose rates depends mainly on the accuracy of the ozone column (OMI Algorithm Theoretical Basis Document III). The total root mean square (RMS) error is $3 \%$ for a SZA of $50^{\circ}$, while this RMS error increases for increasing SZA and for shorter UV-B wavelengths. Thus, OMI erythemal retrieved values are expected to present a SZA dependence, with increasing uncertainties in higher SZAs.

In order to investigate the SZA dependence of the OMI dataset, the exact overpass time match was used to avoid discrepancies due to different SZA ranges within an hour between winter and summer periods. In Figure 3, the relative percentage differences between OMI and NILU (left panel), and OMI and UVB-1 (right panel) were plotted against the SZA at the time of the satellite overpass (upper panels). Median differences of $5^{\circ}$ SZA bins were also investigated (lower panels), while the $20 / 80$ percentile range is also given in the form of error bars. 

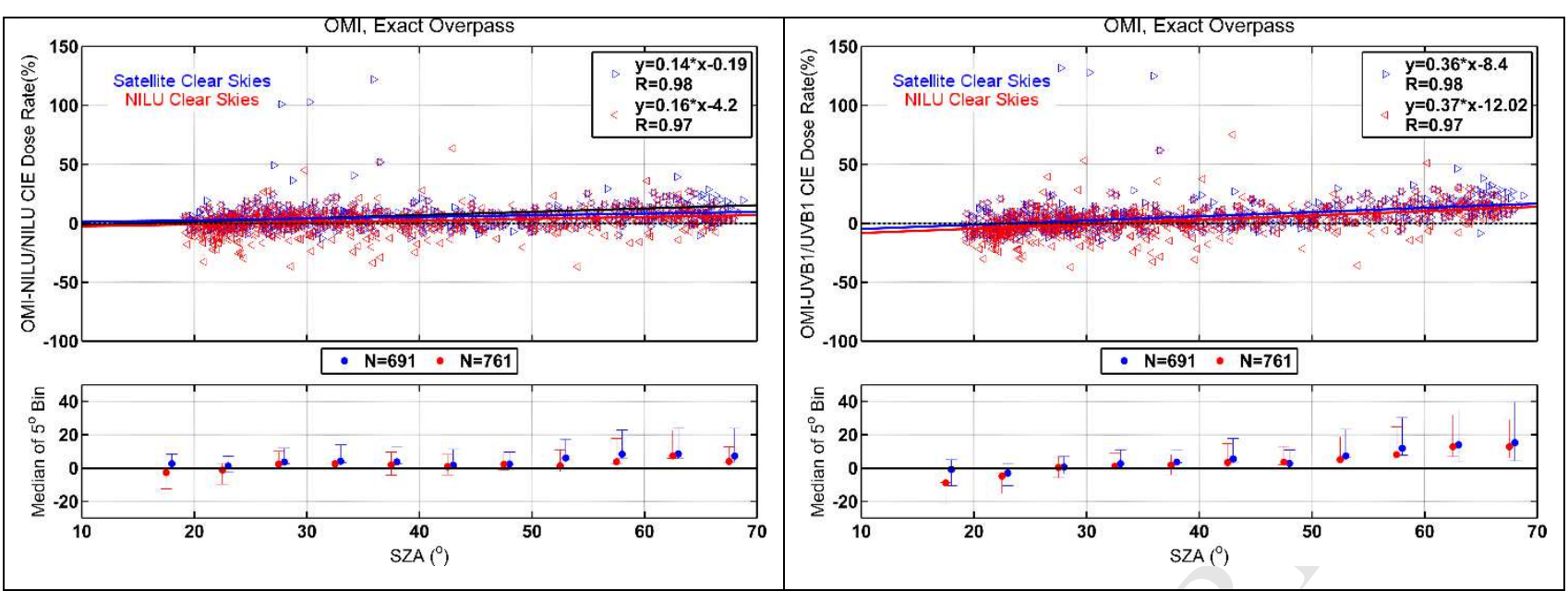

Figure $3 \mathrm{SZA}$ dependence of the relative percentage differences between the NILU and OMI erythemal dose rates (left panel) and the UVB-1 and OMI (right panel) at the exact OMI overpass time under cloud-free instances. Cases where the OMI LER values are less than 0.1 are characterized as OMI Clear Skies and are depicted in blue, while data identified as cloud-free based on NILU PAR measurements, are indicated as NILU Clear Skies and are depicted in red. The linear regression equations are also displayed while the correlation coefficient ${ }^{\circledR}$ between the original datasets OMI/NILU and OMI/UVB-1 is also provided (upper panels). Median relative percentage differences of $5^{\circ} \mathrm{SZA}$ bins are presented along with the $20 / 80$ percentile values depicted as error bars (lower panels).

Based on Figure 3, left panel, there is no significant evidence of a SZA dependence between the OMI and NILU estimates. When moving to higher SZA values, above $55^{\circ}$, the $20 / 80$ percentile range becomes wider even for the cloud-free data points, implying that at the higher observed solar elevations, the two datasets present higher scattering that possibly led to an ascending small trend in the slopes of the regression lines. On the right panel of the same figure, the exact same comparison plots are given for the OMI and UVB-1 retrievals. For this later comparison, as seen in the lower panel, there is a stronger SZA dependence for SZAs above $50^{\circ}$, with higher slopes, almost double the slopes seen in the OMI/NILU comparisons, and lower y intersect values. This aspect could be probably attributed to the UVB-1 dataset that was not corrected for its non-ideal angular response. Still, all datasets present high correlation coefficients $(>0.97)$ in all cases, with the stronger correlation observed under the satellite clear skies restrictions.

540 Generally, as seen in the lower panels of Figure 3, OMI erythemal values presented a relatively 541 small SZA dependence that resulted in higher overestimation of the product for SZAs above $60^{\circ}$ for 542 the greater area of Thessaloniki, Greece; therefore, OMI data should be treated with caution for SZAs exceeding $60^{\circ}$.

\subsection{The Ozone dependence}


on average OMI underestimates the TOC levels by $\sim 2 \%$. Since the OMI algorithm utilizes the TOC

548 information to derive the erythemal dose rates, the differences seen in TOC are expected to 549 influence the relative percentage differences of the retrieved values between the satellite- and ground-based instruments. To explore the influence of the TOC, OMI TOMS TOC estimations were compared against the NILU TOC values retrieved by a NN developed for this specific purpose (Zempila et al., 2017a). In Figure 4, the relative percentage differences seen in erythemal dose rates between OMI and NILU are plotted against the relative percentage differences in TOC between OMI and NILU under cloud-free cases for the 1-hour averages around the OMI overpass time.

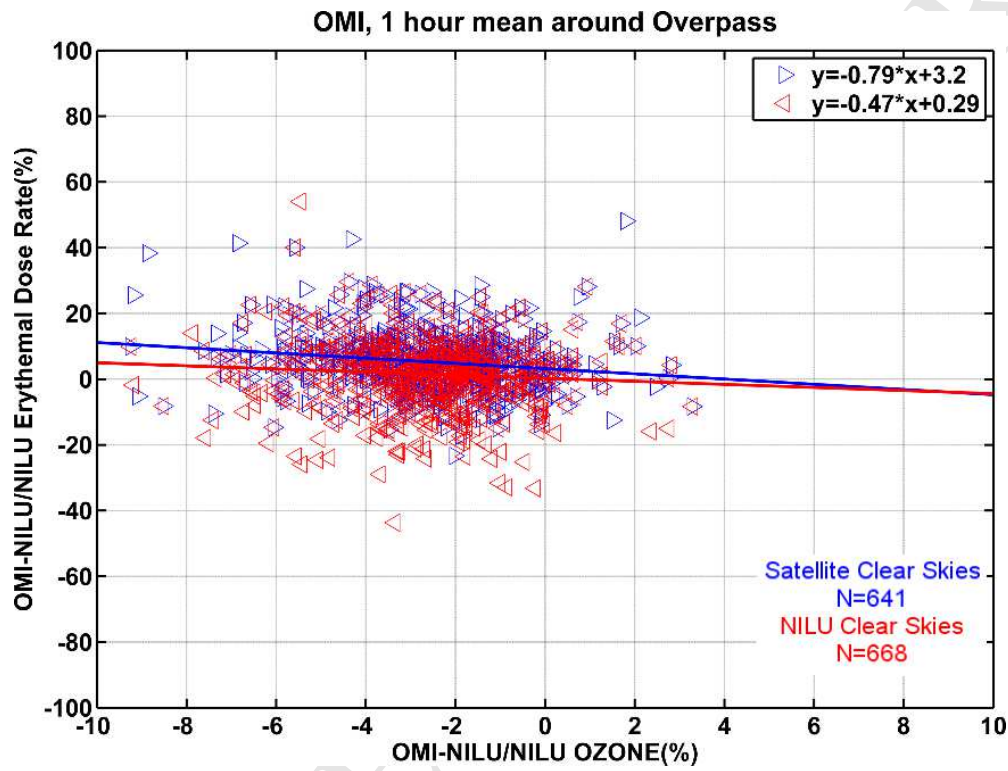

Figure 4 Erythemal relative percentage differences between OMI and NILU data against TOC relative percentage differences again between OMI and NILU. The linear least square fits are also presented. The comparisons are performed only for cloud-free cases for the 1-hour averages around the OMI overpass time using the OMI cloud restriction (LER<0.1) and the NILU PAR based cloud restriction (Cloud-free 1-minute data $>70 \%$ ).

For the comparisons between OMI and NILU presented in Figure 4, most of the differences seen in the TOC values lying within $\pm 3 \%$ ( $\mathrm{x}$-axis range). As expected, when OMI TOMS TOC values are less than the corresponding retrieved by NILU measurements, OMI is higher than the NILU derived ones. This fact results to descending slopes for both OMI and NILU defined cloud-free skies that were proved statistically significant via F-test (stronger significance was seen in the satellite clear skies cases where the $\mathrm{p}$ value was of the order of $10^{-5}$ ) performed on the datasets. In general, a mean underestimation of $2 \%$ in TOC by OMI under cloud-free conditions, as stated by Zempila et al. (2017a), can lead to an average overestimation in the OMI data of $1 \%$ to 5\%, for the NILU clear skies and OMI clear skies respectively. Consequently, users are suggested to bear in mind that a 
part up to $5 \%$ of the overestimation in OMI data could be introduced from deviations seen in OMI

571 TOC retrieved values under clear skies.

\subsection{The Aerosol dependence}

574

Due to the imperfect knowledge of the optical properties of the aerosols, non-absorbing and absorbing ones, and pollutants in the boundary layer, the retrieval of the OMI UV products is limited and the comparisons with ground-based data are expected to be influenced by deviations of AOD from the values that OMI uses to derive its UV products (Arola et al., 2009).

To investigate the effect of aerosols in the observed relative differences between satellite- and ground-based erythemal data, aerosol optical depths at $340 \mathrm{~nm}$ from the CIMEL sunphotometer that operates in Thessaloniki, were also used (Balis et al., 2010). According to Kazadzis et al. (2007), aerosol optical depths in UV experience a seasonal variation in Thessaloniki, with higher AOD values at $340 \mathrm{~nm}$ retrieved in August and lower values in December. Furthermore, in Thessaloniki, the aerosols are a contribution of marine, mineral dust and anthropogenic sources that make the aerosol scene more complex. In the same study, back trajectories proved that additionally to local aerosol sources, transport of aerosols takes place, especially during the summertime. It was proven that air masses coming from the North and North Eastern directions result in high aerosol loads over Thessaloniki, while minimum AOD is associated with air masses originating from the Atlantic Ocean. These findings clearly denote that in Thessaloniki the aerosol optical depths are a result of a rather complex mixture that makes the AOD retrieval by space-born instruments a non-trivial task (Koukouli et al., 2006).

CIMEL provides measurements of aerosol optical depths since 2011, thus only 4 years of measurements were available for this evaluation. Again, the datasets were distinguished into two categories, one comprising for the cases were the OMI detected LER values below 0.1, while the second set only included measurements during which the NILU cloud detection algorithm resulted into more than $70 \%$ cloud-free moments within the hour around the overpass. In order to increase the data points, 1-hour averages around the overpass time were taken into account, while the NILU and B086 data were used to minimize any influence of the SZA dependence seen in the OMI/ UVB1 comparisons (Figure 3). Although the statistical sample is small, OMI erythemal dose rates showed a slight dependence on the aerosol load at the site, especially in high AOD values, in both discriminations of cloudless cases and comparisons; OMI/NILU is shown in Figure 5 (left panels) and OMI/B086 in Figure 5 (right panels). This behaviour can probably be attributed to the way that 
the correction on OMI UV irradiances is performed based on monthly AOD and SSA climatology at $315 \mathrm{~nm}$ (Arola et al., 2009), that probably cannot interpreter high aerosol loads at the station. Cases with more than 0.7 AOD cover for the OMI cloud-free skies occupied $3.2 \%$ of the total dataset, while under the NILU cloud-free limitation this percentage augmented to $6 \%$.

606
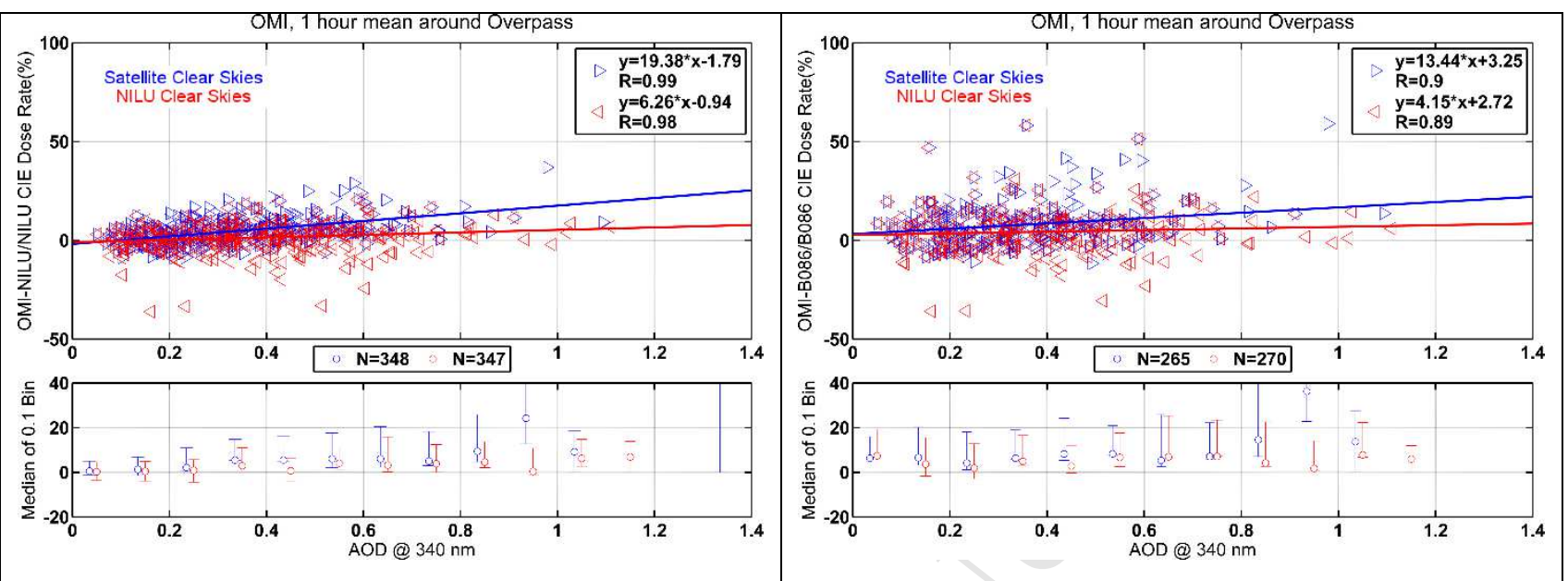

Figure 5 Erythemal relative percentage differences between OMI and NILU (left panel), and OMI and B086 (right panel)

data against AOD estimations from a CIMEL sunphotometer at $340 \mathrm{~nm}$. The least square linear fits are also presented, while the correlation coefficients between the OMI/NILU and OMI/B086 datasets are also depicted (upper panels). The median relative percentage differences of the relative erythemal dose rate differences within 0.1 bin of AOD are provided in the lower panels, while the $\mathbf{2 0 / 8 0}$ percentiles are depicted as error bars. The comparisons are performed only for cloud-free cases for the 1-hour averages around the OMI overpass time using the OMI cloud restriction (LER<0.1) and the NILU PAR based cloud restriction (Cloud-free1-minute data $>70 \%$ ).

Based on the findings in Figure 5 (left panel), under the NILU defined cloud-free cases, the average overestimation of the OMI erythemal dose rates is $\sim 6.3 \%$ per AOD at $340 \mathrm{~nm}$ unit. Since the average $\mathrm{AOD}$ at $340 \mathrm{~nm}$ during the examined period is $0.43 \pm 0.25$, the expected average percentage overestimation of OMI values is $2.8 \% \pm 1.6 \%$. This number was tripled when examining the OMI cloud-free cases. Similar behaviour was observed for the OMI/B086 comparisons, but smaller slopes were obtained, verifying that OMI tends to overestimate the erythemal dose rates for cases where high aerosol loads were measured at Thessaloniki. It should be also highlighted that the OMI/NILU comparisons presented high correlation coefficients $(>0.98)$ in all cases, while the OMI/B086 comparisons showed lower correlation coefficients mainly due to the way that the time match was performed due to the smaller number of B086 spectra measurements. Nevertheless, the obtained comparisons showed better agreement between OMI and ground-based measurements than the one revealed by Kazadzis et al. (2009) since the OMI algorithm currently corrects the UV products for absorbing aerosols based on the study by Arola et al. (2009). Users 
could combine the information provided by OMI regarding the retrieved AOD values in order to assess the accuracy of OMI erythemal product and/or apply an upper cut-off limit to achieve better agreement between ground- and satellite-based erythemal values.

\subsection{The Cloud dependence}

Since the OMI algorithm interprets clouds as a uniform cover over the pixel, an analysis on the effect of clouds should take place in order to evaluate the performance of the satellite algorithm under various cloudiness conditions. As mentioned before, OMI provides an estimation of the COT seen within the pixel at the exact overpass time. In addition, the study by Vasaras et al. (2001) uses 8-minute averages of 1-minute measurements of GHI from a CM21 pyranometer that is operating at LAP/AUTh since 1993, to determine whether the measurement was taken under stable or unstable cloudy conditions or under unoccluded sun disk. In order to investigate the influence of the clouds on the relative differences, overpass exact time matching data (coincidence within one minute) under all skies conditions were used. The sun disk coverage information provided by the CM21 cloud description algorithm introduced by Vasaras et al. (2001), was also included into the comparisons. Based on the algorithm, cases where the sun disk was completely covered by clouds were identified as "stable-cloudy" conditions, while "unstable-cloudy" conditions stated the state where the sun was partially covered by clouds. The cases where clouds were present in the horizon and were identified by the NILU PAR cloud-screening algorithm, but the CM21 algorithm resulted to unobstructed sun disk were identified as "unoccluded sun disk" instances. Results of the comparisons under these three cloud identified circumstances, are shown in Figure 6.
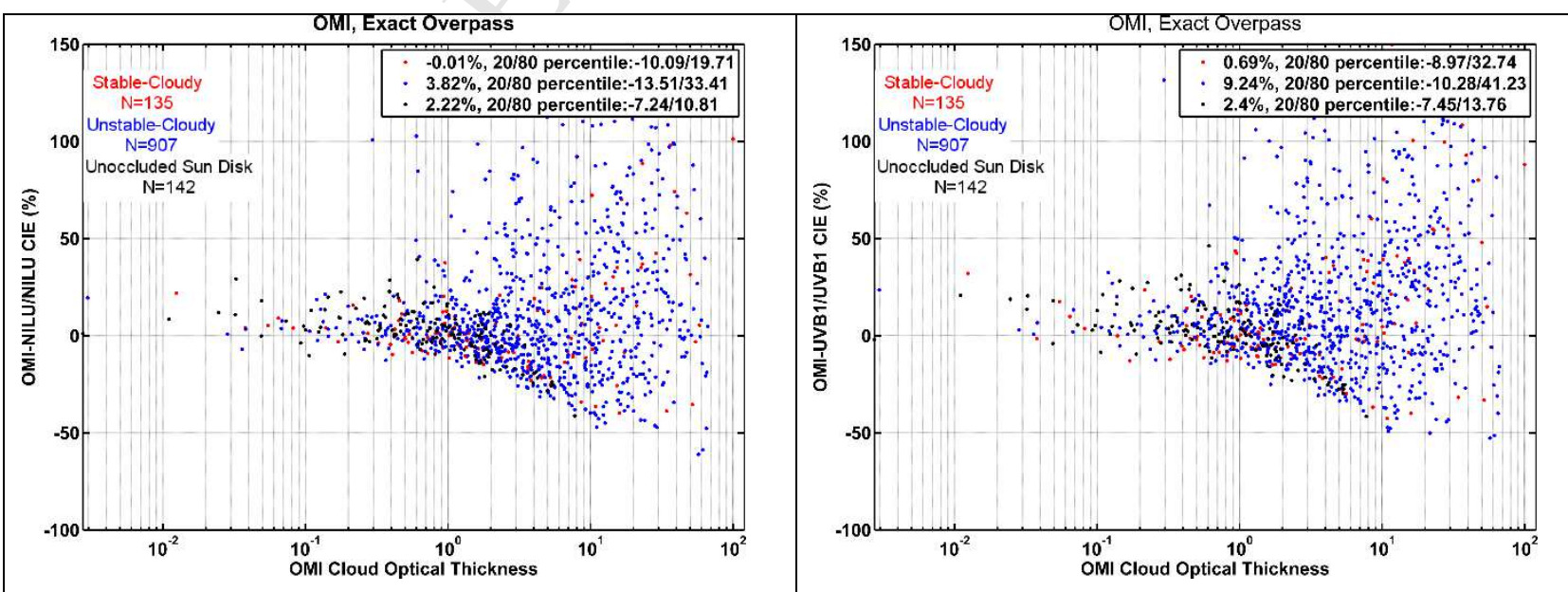

Figure 6 Relative percentage differences of the OMI and NILU (left panel), and OMI and UVB-1 (right panel) derived 
erythemal dose rates are presented at the exact overpass time against the COT values reported by OMI in a logarithmic $\mathrm{x}$ axis (upper panels). Three cases were distinguished based on the CM21 cloud-flagging algorithm: (i) Stable-Cloudy conditions during which the sun disk is completely obscured, (ii) Unstable-Cloudy conditions during which the sun disk is partially covered by clouds, and (iii) Unoccluded sun disk during which NILU PAR algorithm detects clouds while the CM21 algorithm reports unobscured sun disk. Median differences along with the 20/80 percentile range are also depicted.

As seen in both panels of Figure 6, the discrepancies between the two sets, ground- and satellitebased, become higher with higher cloud optical thicknesses seen by the satellite sensor that could be attributed to the fact that at higher COT values, irradiances are too low resulting to higher relative percentage differences. Since OMI receives backscattered irradiances from an area between 13×24 $\mathrm{km}^{2}$ in the nadir to $24 \times 102 \mathrm{~km}^{2}$ on the edges of the OMI swath, the optical geometry is significantly different from the single point measurements that NILU and UVB-1 perform. The presence of scatter clouds over the horizon can lead to complicate radiation scenes that are impossible to capture by nadir-viewing satellite measurements. For larger COT values, the scene seen in both OMI/NILU and OMI/UVB-1 comparisons was rather complicated, with cases where OMI underestimated (negative relative percentage differences) and cases where OMI overestimated (positive relative percentage differences). For both panels in Figure 6, there was an unequal spread of the percentage differences, where cases during which OMI overestimated resulted in higher comparison numbers $(>50 \%)$, while the cases during which OMI underestimated the erythemal dose rates resulted in relative differences greater than $-50 \%$. This fact, along with the fact that the number of points with positive relative percentage differences, 1191 for the OMI/NILU comparison and 1234 for the OMI/UVB-1 respectively, was larger than the one with negative differences, 822

672 for the OMI/NILU and 755 for the OMI/UVB-1 comparisons respectively, led to an average 673 overestimation in OMI retrievals.

674 To further investigate this aspect, histograms of the relative percentage differences were examined 675 for the 3 cloudiness conditions where the LER values reported by OMI were more than 0.1 (LER>0.1), in order to verify that the OMI was also seeing clouds into the pixel. 


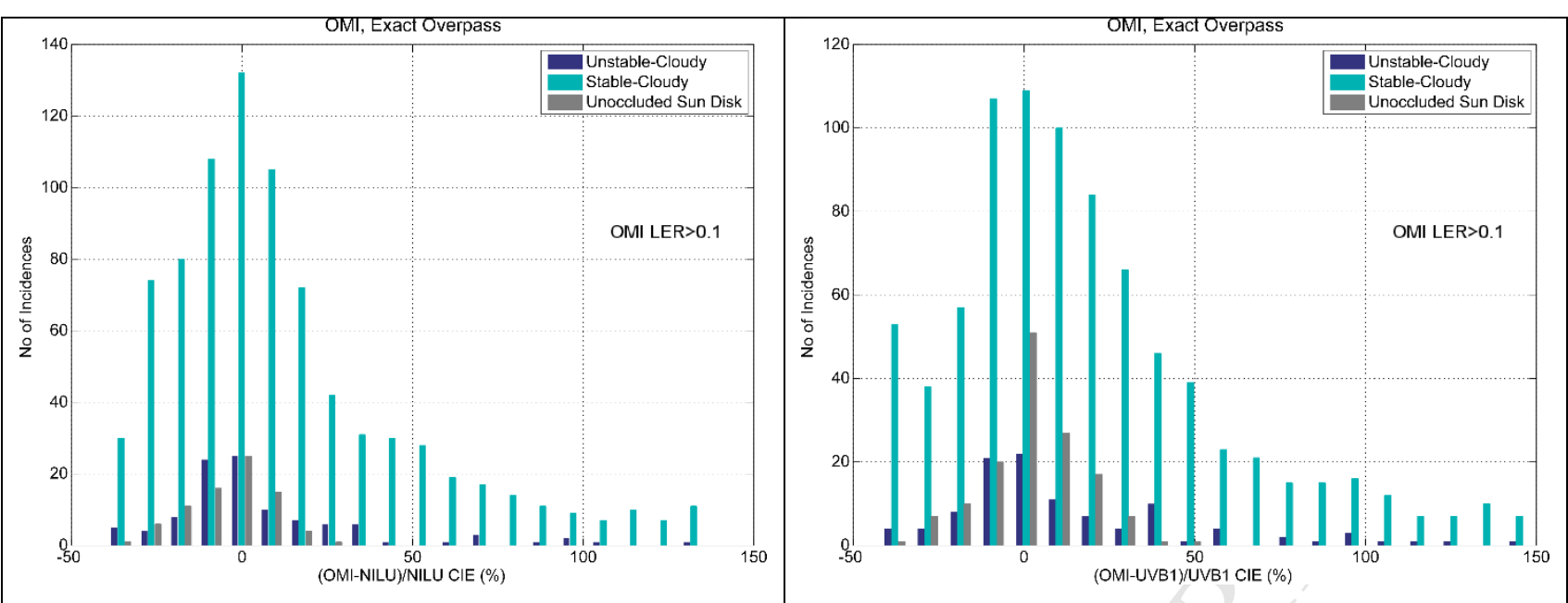

Figure 7 Histograms of relative percentage differences between OMI and NILU (left panel), and OMI and UVB-1 CIE (right panel) dose rates for three cloudiness conditions (as described in Figure 6). The results are presented for cases where the OMI LER values were more than 0.1 (LER>0.1).

The histograms in Figure 7 revealed distinct patterns among the three cloudiness condition groups that are consistent in both NILU/OMI and UVB-1/OMI comparisons. Under a partially covered sun disk (unstable cloudy conditions), both distributions in the left and right panel of the figure, are wide, with low count numbers, while OMI seems to underestimate the NILU erythemal dose rates since the majority of the points were piled into the negative relative percentage difference area (left panel). This behaviour could be partially attributed to the fact that OMI treats clouds as homogenous while it assumes that they cover the whole pixel of interest. Thus, when direct radiation is present, OMI tends to underestimate the erythemal values. Furthermore, a weak secondary peak seemed to be present in the OMI/UVB-1 comparisons under unstable cloudy conditions (right panel of Figure 7) leading to higher number of positive percentages, probably due to SZA dependencies as discussed to a previous section (Section 4.1) and/or low area of unobscured sun disk.

When limiting the datasets to instances where the sun was completely covered by clouds (stable cloudy conditions as they are referred to in Figure 7), the distribution is quite wide and skewed towards positive relative differences, which declares that OMI overestimates the corresponding ground-based values for most of these cases. Furthermore, again in OMI/UVB-1 and possibly in OMI/NILU comparisons, there is a secondary weaker peak implying that under certain conditions when the sun disk is completely covered, OMI tends to overestimate the erythemal dose rates by $45 \%$ or more. In this occasion, the exact position of the station does not interfere with the results, since the diffuse radiation dominates during these cloudiness conditions, something that is not the case for the other two classified groups (unstable cloudy and unoccluded sun disk). An 
underestimation of the cloud optical thickness by OMI could lead to higher erythemal retrieved rates than the corresponding ground-based values.

704 For the cases under which the sun was uncovered, the distribution of the percentages is narrower when compared to the other two cloudiness cases, and the peaks were approaching zero percentage values for both the OMI/NILU and OMI/ UVB-1 comparisons. For these occasions, one would expect the OMI to retrieve in general lower erythemal values than the real ones, since the retrieval algorithm assumes that clouds cover the whole pixel, while an unoccluded sun disk would result in higher direct irradiances and thus higher erythemal values.

Although the major difference between these comparisons results from the fact that OMI measurements represent the mean surface erythemal dose rates over a wide region rather than at a point as is the case with ground-based data. In such comparisons, OMI tends to overestimate the erythemal dose rates under cloudy conditions. However, very large differences revealed for very high COTs $(>10)$ in figure 6 , are linked with GHI attenuation on the order of $~ 300 \%$ compared with cloudless skies. Therefore, these differences were affecting the statistical evaluation but in practise, they were differences seen during very low irradiance levels. OMI data users are encouraged to examine thoroughly the cloudiness information provided by OMI (LER, COT) in order to concatenate accordingly the dataset based on their study purposes.

\subsection{The UV index comparisons}

Although UV index (UVI) and erythemal data are expressions of the same biological parameter the erythema of the human skin when exposed to UV solar radiation - in most health related studies, the UV index is the common parameter describing the effects of exposure to solar UV radiation (WHO, WMO, UNEP, ICNIRP, 2002; Lucas et al., 2006; Eide \& Weinstock, 2005; Gonçalves et al., 2011; among others). The instant UVI is in fact the erythemal dose rate (in $\mathrm{W} / \mathrm{m}^{2}$ ) multiplied by 40 (Vanicek et al., 1999; WHO, WMO, UNEP, ICNIRP, 2002). This measure was first formulated in Canada to result to a maximum value of 10 at that region, while it was adopted by the World Meteorological Organization 2 years later, in 1994 (WHO, WMO, UNEP, ICNIRP; 2002, Fioletov et al., 2010) as a means of an easier interpretation of the UV exposure risks and rise of public 730 awareness.

731 Nowadays, NASA's Earth data webpage (https://earthdata.nasa.gov/earth-observation-data/nearreal-time/download-nrt-data/omi-nrt) provides OMI UVI data in near real-time (average latency: 100-165 minutes which is expected to be reduced in near future), thus supporting the efforts for 
timely distribution of data related to earth observation, environment protection and public awareness.

736 Since for health studies the higher values of UVI are of most importance during which the impact of solar UV exposure is more immense, the study focused on the cases were the OMI UVI was lower than the NILU detected one. Among the ground-based available measurements, the NILU data were chosen to depict this aspect due to better statistic results (Section 4). Here only the discrimination between satellite cloud-free cases $(\mathrm{LER}<0.1)$ was imposed onto the datasets since this information is available to all data users, while the 1-hour mean values around the overpass time were investigated to maximize the number of coincidences.

To depict this aspect relative percentages (Number of cases where $\mathrm{UVI}_{\mathrm{OMI}}<\mathrm{UVI}_{\mathrm{NILU}}$ over the total number of coincidences within the OMI UVI bin) for each OMI UVI bin of 1 unit width were plotted in Figure 8. The differences between the UVIs, OMI and NILU, were classified in differences of 0.1 as presented in the colour bar of Figure 8. For the "Low (UVI<3)" UVI levels, OMI underestimated up to $10 \%$ the UVI values, but for these cases the impact on humans and ecosystems is low due to the low intensity of the UV radiation. For the moderate UVI range $(3 \leq \mathrm{UVI}<6)$, OMI had a maximum underestimation of 0.9 when compared to the NILU UVI for the bins of 4-5 and 5-6. This would not affect the set alerts on the UVI levels, since even with this underestimation the OMI derived UVI would result in the moderate UVI classification. For the high UVI levels $(6 \leq \mathrm{UVI}<8)$, the differences observed in the 6-7 OMI UVI bin could lead to a false indication of moderate UVIs, since differences between 0.9 and 1.1 were observed. However, these cases only occupy $2 \%$ of the points in this particular bin. For the adjacent bin of 6-7 OMI UVIs, although differences can reach up to -0.6 with OMI underestimating, the outcome UVIs would be still characterized as high, thus the proposed protection measures for this level of UVIs would not be altered. The same applied to the characterized as high UVIs (8-10), where the maximum underestimation was -0.6 in the 8-9 bin. Although this underestimation in OMI UVIs is relatively high, it would not affect the alert on the UVI levels since it would result to a high UVI classification.

761 Thus, we can conclude that OMI UVI values are reliable when concerning the characterization of 762 the ambient UV radiation impact as low, moderate, high and very high in the greater area of 763 Thessaloniki for the period 2005-2014 under cloud free skies where the impact of exposure to solar 764 UV radiation is more intense. 


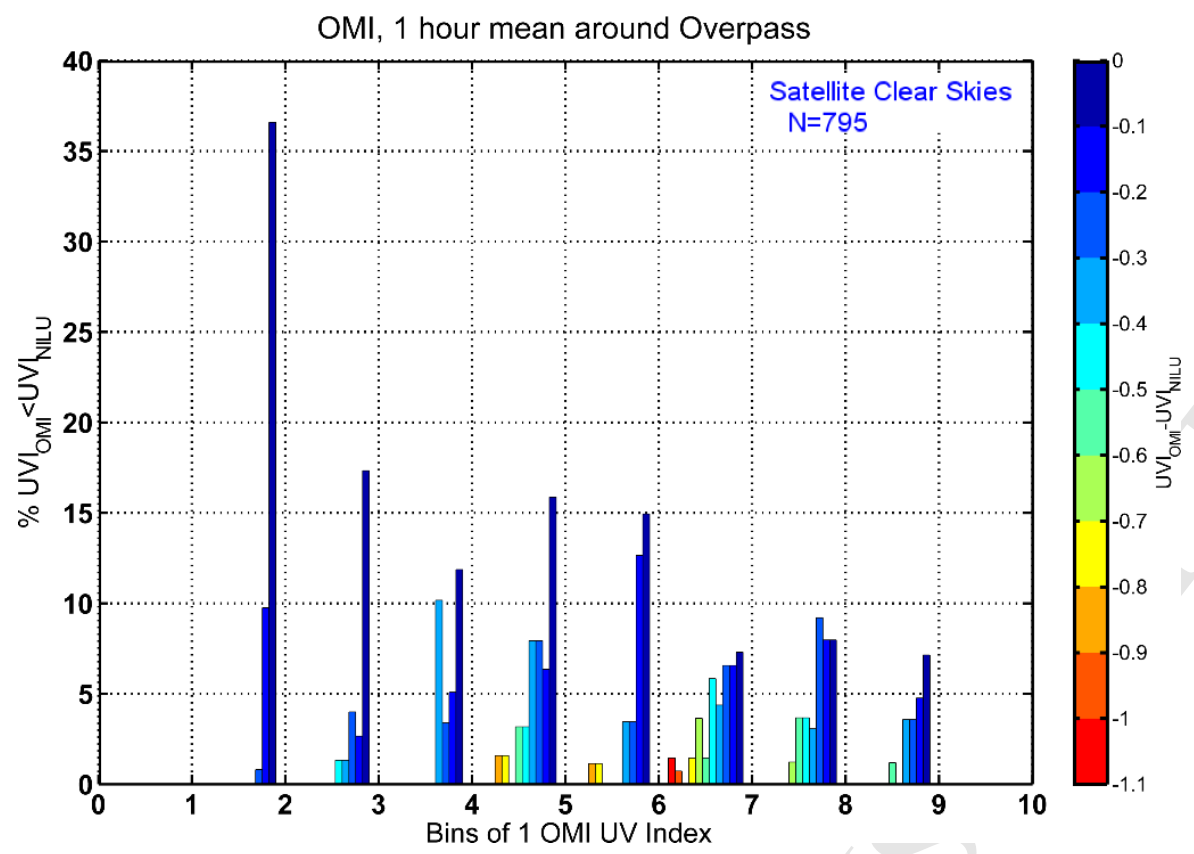

Figure 8 Percentages of the number of cases where OMI UVIs were found to be lower than the corresponding NILU UVI for each bin of 1 OMI UVI under the OMI defined clear skies. Within each OMI UVI bin the difference between the two UVIs, OMI and NILU, are depicted is different color bars.

\section{CONCLUSIONS}

In this study ground-based measurements, model estimates, and satellite retrievals of CIE effective dose rates have been formed, compiled and associated to thoroughly analyse their accuracy at the mid-latitude UV and Ozone monitoring station in the Laboratory of Atmospheric Physics of the Aristotle University of Thessaloniki, Greece.

A NN was trained on NILU-UV multi-filter radiometer irradiance data at 5 different UV wavelengths together with collocated spectra from a Brewer MKIII spectrophotometer to produce 1-minute time series of erythemal dose rates. Furthermore, the NN erythemal dose rates were compared with UVB-1 measurements at the same temporal resolution (1 minute) to provide the level of agreement between the two ground-based datasets. The comparisons between the mean hourly values between the UVB-1 and NILU CIE dose rates revealed a good agreement of $0.86 \%$ under all skies with $20 / 80$ percentiles within the uncertainty of the original measurements themselves.

In the context of space born CIE dose rates, estimates from the OMI/Aura instrument were used. The NASA Aura Data Validation Center provides overpass files including the OMI global attributes and geolocation along with all instrument data fields. Under the data fields subsection, the 
erythemal dose rates are provided at the exact overpass time and at the solar local-noon along with the UV algorithm quality flags (UVBQF) and the UVI values. For all the comparisons performed in this study, satellite collocations within a radius of $50 \mathrm{~km}$ from Thessaloniki were taken into account, while differences of absolute value of $150 \%$ and more between satellite and ground erythemal data were omitted.

792 The comparisons of the ground products with the satellite retrievals revealed the following major 793 points:

- For the nominal comparisons at the exact overpass time, OMI erythemal dose rates overestimated the NILU-UV retrieved values by $2.5 \%$, while this difference was increased to $3.9 \%$ when compared to the UVB-1 data. Under cloud-free cases detected by the PAR cloud binary detection algorithm, the percentage of the OMI overestimation fell to $\sim 2 \%$ for both NILU-UV and UVB-1 comparisons.

- For the local noon exact comparisons, OMI presented higher erythemal dose rates of about 800 $4.1 \%$ when compared to NILU, slightly higher at $5.3 \%$ for the OMI/UVB-1 comparisons. When limiting the data set to cloud-free cases, the agreement between the satellite and groundbased estimates was improved, with relative percentage differences between $2-3 \%$ for the NILU-defined cloud-free cases.

In order to compensate for the OMI footprint and for any changes in cloud position and optical properties, 1-hour averages around the overpass time were also considered.

- The time averaging favors the number of coincidences by a $15 \%$ increase. Under all sky cases, OMI overestimated on average the erythemal dose rates at the overpass time by $3.6 \%$ when compared to NILU and by $6.6 \%$ when compared to UVB-1 data. Higher relative percentage differences were seen when OMI data were related to B086 estimates ( 7\%). These numbers were decreased when the under investigation datasets were limited to cloud-free skies: $2.8 \%$, $2.7 \%$ and $4.6 \%$ for the OMI/ NILU-UV, UVB-1 and B086 comparisons respectively.

- The time averaging of 1-hour around the solar local-noon time under all sky conditions, had not major impact on the comparisons between OMI and NILU-UV and B086. When limiting the

816 For the comparisons performed, the limitation of the OMI data based on the UVBQF was also 817 investigated: 
- The imposed limitation decreased the available dataset by almost $36 \%$, while it did not significantly improved the comparison statistics of any of the above-mentioned schemes: exact and 1-hour averages around overpass and solar local noontime, and cloudiness conditions.

In general, all comparison schemes (different ground-based instruments, averaging practices, comparison limitations) presented similar, moderate relative percentage differences, with OMI CIE data being higher than the corresponding ground-based. In more details:

- Overpass comparisons resulted in better comparative statistics than the noon comparisons, since OMI estimates its noontime UV products based on the measurement performed at the overpass without taking into account changes in ozone, aerosols and clouds.

- Cloud-free cases defined by the NILU PAR algorithm provided a more strict limitation than the OMI defined clear cases where the upper limit of LER $<0.1$ might result in clouds present within the OMI pixel.

Seasonal effects in the satellite estimates were also investigated through SZA, ozone, aerosols and cloud dependences of the relative percentage differences between OMI and ground-based measurements.

- OMI CIE retrieved values are expected to present a SZA dependence for SZAs above $50^{\circ}$ due to higher uncertainty in the ozone retrievals. The comparisons between OMI and NILUUV/UVB-1 data, showed a tendency of OMI to overestimate CIE dose rates for SZA above $60^{\circ}$, which was obvious for both all and cloud-free skies.

- A mean underestimation in OMI TOC values by $2 \%$ under cloud-free conditions led to an overestimation of $1 \%$ to $6 \%$ in the OMI CIE data under clear skies cases.

- Compared to the Kazadzis et al. (2009) study, the results presented here were improved due to the aerosol correction applied to all UV products based on Arola et al. (2009). On average OMI overestimated by $\sim 6.5 \%$ per aerosol optical depth (AOD) at $340 \mathrm{~nm}$ unit when compared to NILU data. The average AOD at $340 \mathrm{~nm}$ during the examined period was $0.43 \pm 0.25$, therefor the expected average percentage overestimation of OMI CIE values due to imperfect aerosol treatment in the algorithm is $2.8 \pm 1.6 \%$.

Since OMI algorithm treats clouds as a uniform layer over the entire pixel, different types of cloudiness were investigated based on the stable cloudy (fully covered sun disk), unstable cloudy 
850 (partially covered sun disk) and unoccluded sun disk indications acquired by the CM21 based 851 algorithm.

852 - In general under high COT values the discrepancies observed between the satellite- and ground-based were higher due to low values of absolute irradiances.

- For the cases where stable cloudy conditions were identified (fully covered sun disk), OMI had the tendency to overestimate the ground-based CIE data.

- For the unstable cloudy conditions (partially covered sun disk), the exact opposite pattern was observed, with OMI data underestimating in general the ground-based erythemal dose rates.

- When the CM21 algorithm detected unoccluded sun disk under cloudy conditions, OMI CIE retrievals presented a narrow distribution around zero relative percentage differences, without

863 As the UVI is a mean of alerting the public on harmful effects when exposed to solar UV radiation, 864 OMI overpass UVI data were also validated through NILU estimates:

- OMI UVIs provided higher estimates than the ground-based UVIs in most of the classifications of UVI based alert zones (low, moderate, high, and very high).

- For the cases where OMI UVIs were found to be lower than the NILU retrieved ones, no significant impact on the above mentioned classifications was observed.

Therefore, the UVI classification under cloud-free conditions based on OMI estimates can be used to alert public awareness in the greater area of Thessaloniki.

In conclusion, this comprehensive work elaborated on the accuracy of ground- and satellite-based estimates of erythemal UV dose rates and UVI values, revealing the merits but also the constraints of the methods applied to both type of datasets. Since space-borne data provide global coverage, their UV products can be used to increase awareness of the harmful effects of overexposure to UV radiation and alert public when necessary. Therefore, we believe that such studies are of high importance in order to provide insight regarding future missions and facilitate potential improvements of the future generation of UV measuring space born sensors. 
882 OMI project is managed by NIVR and KNMI in the Netherlands. We thank the OMI International Science Team for the 883 satellite data used in this study. The authors would also like to acknowledge the National Network for the Measurement 884 of Ultraviolet Solar Radiation, uvnet.gr. 
1. A Jebar, M.A., Parisi, A.V., Downs, N.J., and Turner, J.F., 2017. Validation of Ozone Monitoring Instrument UV Satellite Data Using Spectral and Broadband Surface Based Measurements at a Queensland Site. Photochemistry and Photobiology, 93, 1751-1097.

2. Allaart, M.,M. van Weele, P. Fortuin and H. Kelder, 2004. An Empirical model to predict the UV-index based on Solar Zenith Angle and Total Ozone.Meteorological Applications (Royal Met. Society).doi:10.1017/S1350482703001130.

3. Antón, M., Cachorro, V. E., Vilaplana, J. M., Toledano, C., Krotkov, N. A., Arola, A., Serrano (OMI) with Brewer measurements at El 349 Arenosillo (Spain)-Part 1: Analysis of parameter influence. Atmospheric Chemistry and Physics, 10(13), 5979-350 5989.

4. Arola A, Kalliskota S, den Outer PN, Edvardsen K, Hansen G, Koskela T, Martin TJ, Matthijsen J, Meerkoetter R, Peeters P, Seckmeyer G, Simon PC, Slaper H, Taalas P, and Verdebout J., 2002. Assessment of four methods to estimate surface UV radiation using satellite data, by comparison with ground measurements from four stations in Europe.Journal of Geophysical Research107: 4310.

5. Arola, A., Kazadzis, S., Lindfors, A., Krotkov, N., Kujanpa, J., Tamminen, J., Bais, A., di S., Smedley, A and Kinne, S., 2009. A new approach to correct for absorbing aerosols in OMI UV.Geophysical Research Letters, 36, L22805.

6. Bais, A. F., Gardiner, B. G., Slaper, H., Blumthaler, M., Bernhard, G., McKenzie, R., Webb, A. R., Seckmeyer, G., Kjeldstad, B., Koskela, T., Kirsch, P. J., Gröbner, J., Kerr, J. B., Kazadzis, S., Leszczynski, K., Wardle, D., Josefsson, W., Brogniez, C., Gillotay, D., Reinen, H., Weihs, P., Svenoe, T., Eriksen, P., Kuik, F., and Redondas, A., 1996. SUSPEN intercomparison of ultraviolet spectroradiometers. Journal of Geophysical Research: Atmospheres, 106, 12509-12525.

7. Bais, A. F., Zerefos, C. S., and McElroy, C. T., 1996. Solar UVB measurements with the double- and single-monochromator Brewer ozone spectrophotometers. Geophysical Research Letters, 23, 833-836.

8. Bais, A. F., Zerefos, C. S., Ziomas, I. C., Zoumakis, N., Mantis, H. T., Hofmann, D. J., and Fiocco, G., 1985. Decreases in the Ozone and the SO2 Columns Following the Appearence of the El Chichon Aerosol Cloud at Midlatitude. Atmospheric Ozone, Zerefos, C. S. and Ghazi, A. (Eds.), Springer Netherlands.

9. Bais, A.F., Drosoglou, T., Meleti, C., Kouremeti, N., 2013. Changes in total solar irradiance measured at Thessaloniki, Greece since 1993 associated with changes in aerosols.AdvMeteorolClimatolAtmos Phys.

10. Balis, D., Giannakaki, E., Müller, D., Amiridis, V., Kelektsoglou, K., Rapsomanikis, S., and Bais, A., 2010. Estimation of the microphysical aerosol properties over Thessaloniki, Greece, during the SCOUT-O3 campaign with the synergy of Raman lidar and Sun photometer data. Journal of Geophysical Research: Atmospheres, 115.http ://dx.doi.org/ 10.1029 /2009JD013088. 


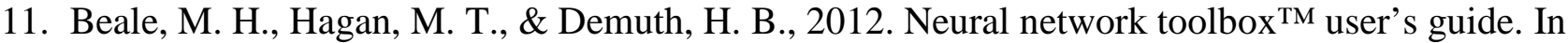
R2012a, TheMathWorks, Inc., 3 Apple Hill Drive Natick, MA 01760-2098.www. mathworks. com.

12. Bernhard, G., Arola, A., Dahlback, A., Fioletov, V., Heikkilä, A., Johnsen, B., Koskela, T., Lakkala, K., Svendby, T., and Tamminen, J., 2015. Comparison of OMI UV observations with ground-based measurements at high northern latitudes. Atmos. Chem. Phys., 15, 7391-7412.

13. Bhartia, P.K., Heath, D. F., and Fleig, A. F., 1985. Observation of anomalously small ozone densities in south polar stratosphere during October 1983 and 1984. Symposium on Dynamics and Remote Sensing of the Middle Atmosphere, 5th Scientific Assembly.

14. Bouillon R., Eisman J., Garabedian M., et al., 2006. Action Spectrum for the Production of Previtamin D3 in Human Skin. CIE Report No 174, Vienna.

15. Cachorro, V. E., Toledano, C., Antón, M., Berjón, A., de Frutos, A., Vilaplana, J. M., Arola, A., and Krotkov, N. A., 2010. Comparison of UV irradiances from Aura/Ozone Monitoring Instrument (OMI) with Brewer measurements at El Arenosillo (Spain) - Part 2: Analysis of site aerosol influence. Atmos. Chem. Phys., 10, 11867-11880.

16. Cadet, J.M., Bencherif, H., Portafaix, T., Lamy, K., Nocingwane, K., Coetzee, G. JR., and Wright, C.Y., 2017. Comparison of ground-based and satellite-derived solar UV index levels at six south African sites. Int. J. Environ. Res. Public Health, E1384.

17. Chubarova Ne, Yurova Au, Krotkov N, Herman J, Bhartia PK., 2002. Comparisons between ground measurements of broadband ultraviolet irradiance (300 to $380 \mathrm{~nm}$ ) and total ozone mapping spectrometer ultraviolet estimates at Moscow from 1979 to 2000. Opt. Eng. 0001;41(12):3070-3081. doi:10.1117/1.1516819.

18. de Laat, A. T. J., R. J. van der A, M. A. F. Allaart, et al., 2010. Extreme sunbathing: Three weeks of small total O3 columns and high UV radiation over the southern tip of South America during the 2009 Antarctic O3 hole season.Geophys. Res. Lett., 37, L14805.doi:10.1029/2010GL043699.

19. Eide M.J., and Weinstock M.A., 2005. Association of UV Index, Latitude, and Melanoma Incidence in Nonwhite Populations-US Surveillance. Epidemiology, and End Results (SEER) Program, 1992 to 2001, Arch Dermatol.,141(4), pp 477-481. doi:10.1001/archderm.141.4.477.

20. Emde C., Buras-Schnell R., Kylling A., Mayer B., Gasteiger J., Hamann U., Kylling J., Richter B., Pause C., Dowling T. and Bugliaro L., 2015. The libRadtran software package for radiative transfer calculations (Version 2.0). Geoscientific Model Development Discussions, VOL. 8.doi: 10.5194 /gmdd-8-10237-2015.

21. Farman, J. C., Gardiner, B. G., and Shanklin, J. D., 1985. Large losses of total ozone in Antartica reveal seasonal ClOx/NOx interaction. Nature, 315, 207-2010.

22. Fioletov V. E., McArthur L. J. B., Mathews T. W. and Marrett L., 2009. On the relationship between erythemal and vitamin $\mathrm{D}$ action spectrum weighted ultraviolet radiation. Journal of Photochemistry and Photobiology B: Biology, 95, 9-16.

23. Fioletov, V., Kerr, J., and Fergusson, A., 2010. The UV Index: Definition, Distribution and Factors Affecting It. Can J Public Health, 101 (4). 
24. Fountoulakis I., Bais A. F., Fragkos K., et al., 2016(a). Short- and long-term variability of spectral solar UV irradiance at Thessaloniki, Greece: effects of changes in aerosols, total ozone and clouds. Atmos. Chem. Phys., 16, 2493-2505.

25. Fountoulakis I., Redondas A., Bais A. F., et al., 2016(b). Dead time effect on the Brewer measurements: correction and estimated uncertainties. Atmos. Meas. Tech., 9, 1799-1816.

26. Foxall, R.J., Cawley, G.C., Dorling, S.R. and Mandic, D.P., 2002. Error functions for prediction of episodes of poor air quality. Artificial Neural Networks-ICANN 2002 (pp. 10311036). Springer Berlin, Heidelberg.

27. Fragkos K., Bais A.F., Meleti C., Fountoulakis I., Tourpali K., Balis D.S., and Zerefos C.S., 2014. Variability of a thirty-year record of total ozone derived from a Brewer spectrophotometer at Thessaloniki and the SBUV version 8.6. E-Proceedings of the XII EMTE National-International Conference of Meteorology-Climatology and Atmospheric Physics, Vol 1.

28. Fragkos, K., A.F. Bais, C. Meleti, I. Fountoulakis, K. Tourpali, D.S. Balis, C.S. Zerefos, 2014. Variability of a thirty-year record of total ozone derived from a Brewer spectrophotometer at Thessaloniki and the SBUV version 8.6. E-Proceedings of the XII EMTE National-International Conference of Meteorology-Climatology and Atmospheric Physics, 1.

29. Fragkos, K., Bais, A. F., Fountoulakis, I., Balis, D., Tourpali, K., Meleti, C., and Zanis, P., 2016. Extreme total column ozone events and effects on UV solar radiation at Thessaloniki, Greece.Theor.ApplClimatol, 505-517.doi: 10.1007/s00704-015-1562-3.

30. Gao, W., D. Schmoldt, and J. R. Slusser., 2009. UV Radiation in Global Climate Change: Measurements, Modeling and Effects on Ecosystems. Springer-Verlag Berlin Heidelberg and Tsinghua University Press, Beijing, China.

31. Garane K., Bais A. F., Kazadzis S., et al, 2006. Monitoring of UV spectral irradiance at Thessaloniki (1990-2005): data re-evaluation and quality control. Ann. Geophys., 24, 3215-3228.

32. Ghil M, Allen MR, Dettinger MD et al., 2002. Advanced spectral methods for climatic time series. Rev Geophys 40(1:3):1-41.

33. Gies, P., Roy, C., Javorniczky, J., Henderson, S., Lemus-Deschamps, L., Driscoll, C., 2004. Global Solar UV Index: Australian Measurements, Forecasts and Comparison with the UK. Photochemistry and Photobiology, 79(1).

34. Gonçalves, F., Guilherme, F., de Souza, S., Luiz, O, Festa-Neto, C., Sanches, J., Chammas, R., Gattas, G., and Eluf-Neto, J., 2011. European ancestry and polymorphisms in DNA repair genes modify the risk of melanoma: A case control study in a high UV index region in Brazil. Journal of Dermatological Science, 64 (1). doi:10.1016/j.jdermsci.2011.06.003.

35. Gröbner, J., Blumthaler, M., Kazadzis, S., Bais, A., Webb, A., Schreder, J., Seckmeyer, G., Rembges, D., 2006. Quality Assurance of spectral solar UV measurements: Results from 26 UV monitoring sites in Europe, 2002 to 2004. Metrologia 43, S66-S71.

36. Herman, J. R., and E. A. Celarier, 1997. Earth surface reflectivity climatology at 340-380 nm from TOMS data. J. Geophys. Res., 102(D23), 28003-28011.doi:10.1029/97JD02074.

37. Holben, B.N., Eck, T.F., Slutsker, I., Tanré, D., Buis, J.P., Setzer, A. ,Vermote, E., Reagan, J.A., Kaufman, Y.J., Nakajima, T., Lavenu, F., Jankowiak, I., and Smirnov, A.A,1998. AERONET-A Federated Instrument Network and Data Archive for Aerosol Characterization. Remote Sensing of Environment, 66 (1), pp 1-16.doi:10.1016/S0034-4257(98)00031-5. 
38. Hornik, K., Stinchcombe M., White, H.,1989. Multilayer Feedforward Networks are Universal Approximators. Neural Networks 2, 359-366. doi:10.1016/0893-6080(89)90020-8.

39. Hülsen, G., Gröbner, J., Bais, A., Blumthaler, M., Disterhoft, P., Johnsen, B., Lantz, K. O., Meleti, C., Schreder, J., Vilaplana Guerrero, J. M., and Ylianttila, L., 2008.Intercomparison of erythemal broadband radiometers calibrated by seven UV calibration facilities in Europe and the USA. Atmos. Chem. Phys., 8, 4865-4875, https://doi.org/10.5194/acp-8-4865-2008.

40. Ialongo, I., Casale, G. R., and Siani, A. M., 2008. Comparison of total ozone and erythemal UV data from OMI with ground-based measurements at Rome station. Atmos. Chem. Phys., 8, 32833289.

41. IPCC 2014: Synthesis Report. Contribution of Working Groups I, II and III to the Fifth Assessment Report of the Intergovernmental Panel on Climate Change [Core Writing Team, R.K. Pachauri and L.A. Meyer (eds.)]. IPCC, Geneva, Switzerland, 151 pp.

42. Karppinen, T., Redondas, A., García, R. D., Lakkala, K., McElroy, C. T., and Kyrö, E., 2014. Compensating for the Effects of Stray Light in Single-Monochromator Brewer Spectrophotometer Ozone Retrieval. Atmosphere-Ocean, pp. 1-8. doi:10.1080/07055900.2013.871499.

43. Kazadzis, S., Bais, A., Amiridis, V., Balis, D., Meleti, C., Kouremeti, N., Zerefos, C. S., Rapsomanikis, S., Petrakakis, M., Kelesis, A., Tzoumaka, P., and Kelektsoglou, K., 2007. Nine years of UV aerosol optical depth measurements at Thessaloniki, Greece. Atmos. Chem. Phys., 7, 2091-2101. https://doi.org/10.5194/acp-7-2091-2007.

44. Kazadzis, S., Bais, A., Arola, A., Krotkov, N., Kouremeti, N., and Meleti, C., 2009b. Ozone Monitoring Instrument spectral UV irradiance products: comparison with ground based measurements at an urban environment. Atm. Chemistry and Physics., 9, 585 - 594.

45. Kazadzis, S., Bais, A., Balis, D., Kouremeti, N., Zempila, M., Arola, A., Giannakaki, E., Amiridis, V., and Kazantzidis, A., 2009a. Spatial and temporal UV irradiance and aerosol variability within the area of an OMI satellite pixel. Atmos. Chem. Phys., 9, 4593-4601. https://doi.org/10.5194/acp-9-4593-2009.

46. Kazantzidis, A., Bais, A. F., Topaloglou, C., Garane, K., Zempila, M. M., Meleti, C., and Zerefos, C., 2006. Quality assurance of the Greek UV Network: preliminary results from the pilot phase operation. Proc. SPIE 6362, Remote Sensing of Clouds and the Atmosphere XI, 636229.

47. Kolehmainen, M., Martikainen, H., Ruuskanen, J., 2001. Neural networks and periodic components used in air quality forecasting. Atmos. Env., 35(5): 815-825.doi:10.1016/S13522310(00)00385-X.

48. Koukouli, M.E., Balis, D.S., Amiridis, V., Kazadzis, S., Bais, A., Nickovic, S., and Torres, O., 2006. Aerosol variability over Thessaloniki using ground based remote sensing observations and the TOMS aerosol index. Atmospheric Environment.

49. Krotkov, N. A., J. Herman, P. K. Bhartia, et al., 2002. OMI Surface UV Irradiance Algorithm, Algorithm Theoretical Baseline Document: Clouds, Aerosols, and Surface UV Irradiance. P. Stammes (ed.), vol. III, ATBD-OMI-03, version 2.0.http://eospso.gsfc.nasa.gov/sites/default/files/ atbd/ATBD-OMI-03.pdf (2 May 2016).

50. Lantz O.K. and Disterhoft P., 1998. Methodology for deriving Clear-sky erythemal calibration factors for UV broadband radiometers of the U.S. Central UV calibration facility. Journal of Atmospheric and Oceanic Technology, Vol. 16 (pp 1736-1752). 
1049

1050

1051

1052

1053

1054

1055

1056

1057

1058

1059

1060

1061

1062

1063

1064

1065

1066

1067

1068

1069

1070

1071

1072

1073

1074

1075

1076

1077

1078

1079

1080

1081

1082

1083

1084

1085

1086

1087

1088

1089

1090

51. Levelt, P.F., van den Oord, G.H.J., Dobber, M.R., Mälkki, A., Visser, H., de Vries, J., Stammes, P., Lundell, J., Saari, H., 2006. The ozone monitoring instrument. IEEE Trans. Geo. Rem. Sens. 44 (5):1093-1101. http://dx.doi.org/10.1109/TGRS.2006.872333.

52. Lucas R., McMichael T., Smith W. and Armstrong, 2006. Solar Ultraviolet Radiation: Global burden of disease from solar ultraviolet radiation. World Health Organization, Public Health and the Environment.

53. Lucas, R., Repacholi, M., and McMichael, A., 2006. Is the current public health message on UV exposure correct?. Bull World Health Organ, 84 (6), Genebra Jun. 2006.doi:10.1590/S004296862006000600018.

54. Mateos, D., Bilbao, J., Kudish, A. I., Parisi, A. V., Carbajal, G., di Sarra, A., Román, R., de Miguel, A., 2013. Validation of OMI satellite erythemal daily dose retrievals using ground-based measurements from fourteen stations. Remote Sensing of Environment, 128, 1-10.

55. McKenzie R.L. and Liley J.B., 2010. UV Radiation in Global Climate Change: Measurements, Modeling and Effects on Ecosystems. Chapter 2: Balancing the risks and benefits of Ultraviolet Radiation. Springer-Verlag Berlin Heidelberg and Tsinghua University Press, Beijing, China.

56. McKenzie, R. L., Seckmeyer, G., Bais, A. F., Kerr, J. B., Madronich, S., 2001. Satellite retrievals of erythemal UV dose compared with ground-based measurements at northern and southern midlatitudes. Journal of Geophysical Research: Atmospheres, 106 (D20). doi: 10.1029/2001JD000545.

57. McKinlay A. F. and Diffey B. L., 1987. A reference action spectrum for ultraviolet induced erythema in human skin. CIE J, 6, 17-22.

58. Meleti, C., Fragkos, K., Bais, A. F., Tourpali, K., Balis, D., and Zerefos, C. S., 2012. Thirty years of total ozone measurements at Thessaloniki with a MKII Brewer spectrophotometer. Quadrennial Ozone Symposium 2012, Toronto.

59. Muyimbwa, D., Dahlback, A., Stamnes, J., Hamre, B., Frette, Ø. Ssenyonga, T., and Chen, YC, 2015. Validation of OMI UV measurements against ground-based measurements at a stations in Kampala, Uganda. EGU General Assembly 2015, Vienna, Austria, id: 2632.

60. Rumelhart, D.E., Hinton, G.E., Williams, R. J., 1986. Learning representations by backpropagating errors. Nature 323, 533-536.

61. Schmalwieser, A. W., Schauberger, G., Janouch, M., Nunez, M., Koskela, T., Berger, D., Karamanian, G., Prosek, P., and Laska, K., 2002. Global validation of a forecast model for irradiance of solar, erythemally effective ultraviolet radiation. SPIE, Optical Engineering, 41 (12).

62. Slaper H., Reinen H. A. J. M., Blumthaler M., et al., 1995. Comparing ground-level spectrally resolved solar UV measurements using various instruments: A technique resolving effects of wavelength shift and slit width. Geophysical Research Letters, 22, 2721-2724.

63. Stammes, P. OMI Algorithm Theoretical Basis Document Volume III, August 2002. https://projects.knmi.nl/omi/documents/data/OMI_ATBD_Volume_3_V2.pdf $\quad(12$ September 2017).

64. Tanskanen A, Krotkov NA, Herman JR, Arola A., 2006.Surface ultraviolet irradiance from OMI.IEEE Transactions on Geoscience and Remote Sensing44(5): 1267-1271.

65. Tanskanen, A, Lindfors, A., Määttä, A., Krotkov, N., Herman, J., Kaurola, J., Koskela, T., Lakkala, K., Fioletov, V., Bernhard, G., McKenzie, R., Kondo, Yutaka., O'Neill, M., Slaper, H., 
den Outer, P., Bais, A., Tamminen, J., 2007. Validation of daily erythemal doses from Ozone Monitoring Instrument with ground-based UV measurement data. Journal of Geophysical Research: Atmospheres, 112 (D24), doi:10.1029/2007JD008830.

66. Tanskanen, A., A. Arola, J. Kujanpää, 2003. Use of the moving time-window technique to determine surface albedo from the TOMS reflectivity data. Proc. SPIE Vol. 4896, p. 239--250.

67. Tanskanen, A., A. Lindfors, A. Maatta ,et al., 2007. Validation of daily erythemal doses from Ozone Monitoring Instrument with ground-based UV measurement data. J. Geophys. Res., 112, D24S44.doi:10.1029/2007JD008830.

68. Taylor, K.E., 2001. Summarizing multiple aspects of model performance in a single diagram. Journal of Geophysical Research, 106 (D7), pp. 7183-7192.

69. Taylor, M., Kazadzis, S., Tsekeri, A., et al., 2014. Satellite retrieval of aerosol microphysical and optical parameters using neural networks: a new methodology applied to the Sahara desert dust peak. Atmos. Meas. Tech. 7, 3151-3175. doi:10.5194/amt-7-3151-2014.

70. Tevini M., 1993. UV-B Radiation and Ozone Depletion: Effects on Humans, Animals, Plants, Microorganism, and Materials. Lewis Publishers, Inc.: Boca Raton.

71. Torres, O.,Tanskanen, A., Veihelmann, B., Ahn, C., Braak, R., Bhartia, P. K., Veefkind, P., Levelt, P., 2007. Aerosols and surface UV products from Ozone Monitoring Instrument observations: An overview. Journal of Geophysical Research: Atmospheres, 112, D24.doi: 10.1029/2007JD008809.

72. van Geffen, R. van der A, M. van Weele, et al., 2005. Surface UV radiation monitoring based on GOME and SCIAMACHY. Proceedings of the ENVISAT \& ERS Symposium, 6-10 September 2004, Salzburg, Austria, ESA publication SP-572.

73. Vanicek, K., Frei, T., Litynska, Z., and Schmalwieser, A., 1999. UV Index for the public. COST-713 Action, Brussels.

74. Vasaras A., Bais A.F., Feister U., and Zerefos C.S., 2001. Comparison of two methods for cloud flagging of spectral UV measurements. Atmospheric Research, 57, 31-42.

75. Webb, A. R., Groebner J., and Blumthaler M., 2006. A Practical Guide to Operating Broadband Instruments Measuring Erythemally Weighted Irradiation. Publication of COST 726 and WMO.

76. Weihs, P., Blumthaler, M., Rieder, H. E., Kreuter, A., Simic, S., Laube, W., Schmalwieser, A. W., Wagner, J. E., and Tanskanen, A., 2008. Measurements of UV irradiance within the area of one satellite pixel. Atmos. Chem. Phys., 8, 5615-5626. https://doi.org/10.5194/acp-8-5615-2008.

77. WMO, 2007. Scientific assessment of ozone depletion 2006. WMO Report No. 50, World Meteorological Organization, Geneva, Switzerland.

78. World Health Organization, International Agency for Research on Cancer, 2008. Vitamin D and cancer. IARC Working Group Reports, WHO Press, 5, 148.

79. World Health Organization, World Meteorological Organization, United Nations Environment Programme,International Commission on Non-Ionizing Radiation Protection,2002. Global solar UV index: a practical guide. Geneva, Switzerland: WHO.http://www.unep.org/pdf/Solar_Index_Guide.pdf.

80. Zempila M. M., Giannaros T. M., Bais A., et al., 2016(b). Evaluation of WRF shortwave radiation parameterizations in predicting Global Horizontal Irradiance in Greece. Renewable Energy, Vol. 86 (pp 831-840). doi:10.1016/j.renene.2015.08.057. 
1133

1134 1135

1136 1137 1138 1139 1140 1141 1142 1143 1144 1145 1146 1147 1148 1149 1150 1151 1152 1153

81. Zempila M. M., Koukouli M. E., Bais, A., et al., 2016(a). OMI/Aura UV product validation using NILU-UV ground-based measurements in Thessaloniki, Greece. Atmospheric Environment, Vol. 140 (pp 283-297). doi:10.1016/j.atmosenv.2016.06.009.

82. Zempila M.M., M. Taylor, M.E. Koukouli, C. Lerot, K. Fragkos, I. Fountoulakis, A. Bais, D. Balis, M. van Roozendael, 2017a. NILU-UV multi-filter radiometer total ozone columns: Comparison with satellite observations over Thessaloniki, Greece. Science of The Total Environment, Volumes 590-591, 15 July 2017, Pages 92-106, ISSN 0048-9697. http://doi.org/10.1016/j.scitotenv.2017.02.174.

83. Zempila M.M., Taylor M., Bais A., and Kazadzis S, 2016(c). Modelling the relationship between photosynthetically active radiation and global horizontal irradiance using singular spectrum analysis. Journal of Quantitative Spectroscopy \& Radiative Transfer, 182, 240-263.

84. Zempila, M.-M., van Geffen, J. H. G. M., Taylor, M., Fountoulakis, I., Koukouli, M.-E., van Weele, M., van der A, R. J., Bais, A., Meleti, C., and Balis, D., 2017b. TEMIS UV product validation using NILU-UV ground-based measurements in Thessaloniki, Greece. Atmos. Chem. Phys., 17, 7157-7174. https://doi.org/10.5194/acp-17-7157-2017, 2017.

85. Zerefos, C. S., 2002. Long-term ozone and UV variations at Thessaloniki, Greece. Physics and Chemistry of the Earth, Parts A/B/C, 27, 455-460.

86. Zerefos, C., 1984. Evidence of the El Chichón stratospheric volcanic cloud in Northern Greece.GeofísicaInternacional, 23.

87. Zerefos, C., and Bais, A., 1997. Solar Ultraviolet Radiation: Modeling, Measurements and Effects. Springer-Verlag Berlin Heidelberg. 
Highlights

- Validation of OMI CIE dose rates against several types of ground-based measurements

- Different ground instruments, averaging practices, limitations, cloud conditions

- The OMI CIE dose rate SZA, Ozone, AOD, and cloudiness dependences were examined

- The OMI UVIs were classified and validated for health related public alerts 